\title{
Making the most of available site information for empirical ground-motion prediction
}

\author{
John Douglas, Pierre Gehl \\ ARN/RIS, BRGM, 3 avenue C. Guillemin, BP 36009, 45060 Orléans Cedex 2, France. \\ Luis Fabian Bonilla, Oona Scotti \\ IRSN/DEI/SARG/BERSSIN, BP 17, 92262 Fontenay-aux-Roses Cedex, France. \\ Julie Régnier, Anne-Marie Duval \& Etienne Bertrand \\ CETE Méditerranée, 56 bd Stalingrad, 06359 Nice Cedex 4, France.
}

December 5, 2008

\begin{abstract}
This article proposes a new framework for the inclusion of site effects in empirical ground-motion prediction equations (GMPEs) by characterizing stations through their onequarter wavelength velocities and assessed confidence limits. The approach is demonstrated for 14 stations of the French accelerometric network (Réseau Accélérométrique Permanent, RAP). This method can make use of all the available information about a given site, e.g. the surface geology, the soil profile, SPT measurements, near-surface velocity estimated from the topographic slope, depth to bedrock and crustal structure. These data help to constrain the velocity profile down to a few kilometers. Based on a statistical study of 858 real profiles from three different regions (Japan, western North America and France) physically-realistic profiles are generated that comply to the information available for each site.

In order to evaluate the confidence limits for the shear-wave velocity profiles and derived site amplifications for each station, a stochastic method is adopted: several thousands profiles are randomly generated based on parameters derived in the statistical study and the constraints available for each station. Then, the one-quarter wavelength assumption is used to estimate the amplification for each station. It is found that a good knowledge of near-surface attenuation (i.e. $\kappa$ or $Q$ ) is mandatory for obtaining precise amplification estimates at high frequencies. Nevertheless, the proposed scheme highlights the important differences in the uncertainties of the site amplifications, depending on the information available for a given station. We suggest that these results could, therefore, be used when developing GMPEs by weighting records from each station depending on the variability in the computed one-quarter wavelength velocities.
\end{abstract}


This approach relies on the assumption that local site effects are only one-dimensional, which is far from true, especially in sedimentary basins. However, most GMPEs only model one-dimensional site effects, so this is not an issue specific to this study. Finally, a way to improve this technique is to use earthquakes or noise recorded at the stations to further constrain the shear-wave velocity profiles and to consequently derive more accurate one-quarter wavelength velocities.

\section{Introduction}

Local site effects have long been recognized as an important factor contributing to variations in strong ground motions (e.g. Boore, 2004). Therefore, the vast majority of empirical groundmotion prediction equations (GMPEs) try to model the differences between ground motions at sites with different local site conditions (e.g. Douglas, 2003). Various approaches have been followed from simple binary soil/rock classifications (e.g. Berge-Thierry et al, 2003) to the explicit use of shear-wave velocity (e.g. Joyner and Fumal, 1984), and also others such as individual site coefficients for each strong-motion station considered (e.g. Kamiyama and Yanagisawa, 1986). These various procedures are discussed by Douglas (2003). The method that can be chosen is dependent on the quality of readily-available information on site characteristics at strong-motion stations. The explicit use of average (measured or estimated) shear-wave velocity down to $30 \mathrm{~m}\left(V_{s, 30}\right)$, with the additional consideration of the effect of basin depth, was adopted by all participants of the PEER Next Generation Attenuation (NGA) project (Abrahamson and Silva, 2008; Boore and Atkinson, 2008; Campbell and Bozorgnia, 2008; Chiou and Youngs, 2008; Idriss, 2008) although Boore and Atkinson (2008) do not find that the basin effect is significant for their model and Idriss (2008) does not include a basin effect in his model. Measuring near-surface wave velocities using conventional methods, such as cross-hole or down-hole techniques, is expensive and time-consuming. Therefore, although such velocities are required, it is unlikely that such measurements will be made at many locations in the near future. In Japan and the United States such measurements are routinely performed. In Europe, however, it is thought that less than 100 strong-motion stations, from a total of over 2953 (European-Mediterranean Seismological Centre, 2007), have had their near-surface wave velocities measured and published.

What all previous approaches have in common is that local site conditions at all stations used to derive GMPEs are assumed to be known to the same detail and with the same accuracy. This is not often true in practice. For example, in the NGA Flat File $V_{s, 30}$ is available for some stations based on measurements (from, e.g., cross-hole or down-hole surveys) (for $35 \%$ of the records) but for other stations (particularly those outside California) the $V_{s, 30}$ values have been 
estimated based on local geology and its correlation with $V_{s, 30}$. In the NGA Flat File these estimated values are clearly indicated and their estimated standard deviations are higher than those from measurements; however, this difference in the accuracy of $V_{s, 30}$ s was not considered by the five GMPE-developer teams.

In addition, the method used to model site effects is invariably limited by the quality of information available for the most poorly characterized station used to derive the GMPEs. For example, Spudich et al (1999) attempted to classify the stations used in their analysis into four categories: hard rock, soft rock, shallow soil and deep soil, but were forced to adopt a simple binary soil/rock classification because information was not available to classify all sites into these four categories (29 records, from a total of 142, were from sites classified as 'unknown soil' or 'unknown rock'). In the extreme situation, if, for example, shear-wave velocity profiles were available for all but one site and for that single site the only information available is that it is a 'rock' site, a simple binary scheme would have to be used thereby throwing away all the invaluable information available in the velocity profiles. In practice it would be more likely that the data from this single station would be dispensed with for the analysis unless the station provides particularly useful data, e.g. records from very close to the source.

An alternative approach is firstly to use a simple classification technique that is obliged by the lack of information for some stations and then, in a second step, to examine the residuals with respect to more complex site characterization parameters, such as $V_{s, 30}$ or basin depth, for those stations with more complete information. This approach has been followed by, for example, Ambraseys (1995) to examine the effect of $V_{s, 30}$ and Field (2000) for examining the effect of sedimentary basins on ground motions. When applying such an approach care needs to be taken to account for possible bias in the distributions with respect to other independent variables for stations where detailed site information is available. For example, Boore and Atkinson (2007) note the strong negative correlation between shear-wave velocity and basin depth for data in the NGA Flat File.

None of these techniques to overcome the heterogeneous nature of local site information is completely satisfactory. Therefore, the aim of this article is to propose a new framework that makes use of all the available information about local site conditions to allow the estimation of mean shear-wave velocity profiles and their confidence limits for each station. The method is a first-order, but robust, proxy for site response estimation. These profiles can then be used to apply the one-quarter wavelength velocity, $V_{s, \frac{1}{4}}$, method to model site effects within GMPEs (Joyner and Fumal, 1984) and a weighting scheme applied during the regression analysis to account for the varying confidence limits of the $V_{s, \frac{1}{4}}$ s. However, no new empirical GMPEs are computed in this article. The following two sections describe the proposed procedure including 
the method to generate a distribution of possible shear-wave velocity profiles for each station. Then in Section 4 the technique is applied to 14 stations of the French accelerometric network (Réseau Accélérometrique Permanent, RAP). Following this, a weighting scheme for use in regression analysis when deriving GMPEs using this approach is proposed. The article closes with a discussion of the merits and disadvantages of the proposed method to evaluate the shear-wave velocity profiles, the $V_{s, \frac{1}{4}} \mathrm{~s}$ and site amplifications using the one-quarter wavelength assumption.

\section{Proposed method}

In the proposed procedure local site conditions are characterized using the average near-surface wave velocities down to a depth equal to one-quarter the wavelength of the wave of interest (e.g. Joyner et al, 1981). Joyner et al (1981), Boore and Joyner (1991) and Boore and Joyner (1997) show that the quarter-wavelength method for assessing site amplification yields good estimates of the site amplification without the requirement of complex computation. The equation to estimate the spectral amplification, $A(f)$, (where $f$ is frequency) at a site is (e.g. Boore, 2003):

$$
\begin{aligned}
A(f) & =\sqrt{\frac{\rho_{s} \beta_{s}}{\bar{\rho}(f) \bar{\beta}(f)}} \\
\text { where } \quad \bar{\rho}(f) & =\frac{1}{z(f)} \int_{0}^{z(f)} \rho(z) \mathrm{d} z \\
\bar{\beta}(f) & =z(f)\left[\int_{0}^{z(f)}\left(\frac{1}{\beta(z)}\right) \mathrm{d} z\right]^{-1} \\
z(f) & =\frac{\bar{\beta}(f)}{4 f}
\end{aligned}
$$

where $\beta(z)$ is the shear-wave velocity at depth $z, \rho(z)$ is the density at depth $z$ and $\beta_{s}$ and $\rho_{s}$ are the shear-wave velocity and the density at the source, respectively. For this study, the site_amp program (Boore, 2005) is used to compute site amplification using this method.

This technique models the effect of the impedance contrast between the underlying bedrock (with a high material velocity) and the softer surface deposits (with a lower material velocity). As waves travel vertically from one medium to another the amplitudes of the waves increase (if the velocity is decreasing towards the surface and losses due to reflection, scattering and anelastic attenuation are neglected) since the energy along a tube of rays is constant.

For this article the one-quarter wavelength technique to assess site amplifications is preferred to full one-dimensional site response analysis using, for example, the Haskell-Thompson method because the associated one-quarter wavelength velocities, $V_{s, \frac{1}{4}} \mathrm{~s}$, can be readily incorporated into the functional form of the GMPEs (Joyner and Fumal, 1984). Site amplifications 
derived from full 1D site response analysis could be directly incorporated into GMPEs but such GMPEs would be difficult to use in practice for sites without assessed amplifications. As will be shown in Section $4 V_{s, \frac{1}{4}} \mathrm{~s}$ can be estimated using our approach even for sites where the knowledge of the sub-soil structure is limited (e.g. those sites only defined by site category). As will be shown in Section 6 [and previously shown by Boore and Joyner (1991)] the one-quarter wavelength simplification for estimating site amplification does not allow the prediction of the resonant peaks due to multiple reflections of waves, which can be predicted by full 1D site response analysis.

To apply this method shear-wave velocity estimates down to a few $\mathrm{km}$ (to compute site amplifications up to long periods, e.g. 10s) for every site considered need to be available. Except for a few special sites, such as Cajon Pass (USA) (e.g. Abercrombie, 1997), measured shear-wave velocities are not available beyond a few tens or hundreds of meters, if at all. However, other information is available that can be used to approximate the shear-wave and density velocity profiles down to the one-quarter wavelength depth. The types of information available to estimate the profiles are discussed in the following paragraph. This information will allow a distribution of possible velocity and density profiles to be defined from which the distribution of possible $V_{s, \frac{1}{4}} \mathrm{~s}$ can be estimated. When more constraints are available, for example when a measured shear-wave velocity profile exists, the distribution of $V_{s, \frac{1}{4}}$ for that station will be narrower than when few constraints are available, for example when the profile is based only on local geological information. In addition, geophysical considerations regarding factors like pressure and temperature variation with depth could eventually be included. However, in practice this type of information is even more difficult to find than shear-wave velocities at each instrumented site. Strong-motion data from stations with well-defined $V_{s, \frac{1}{4}}$ s should be given more weight in the regression analysis than those data from stations with few constraints on these velocities.

Table 1 lists the information that is sometimes available to help constrain shear-wave velocity and density profiles down to a few kms. Obviously not all these sources of information are available for every site. For example, information relying on on-site measurements (e.g. SPT results) are rarely available for strong-motion stations. However, some of these data (e.g. topographic slope) can be calculated based on remote-sensing information and therefore they exist for all sites.

[Table 1 about here.] 


\section{Generation of shear-wave and density profiles}

In this study, a large set of physically-realistic profiles is generated that can then be reduced by the application of constraints from information available at each strong-motion station considered. The generation of these profiles has been made using a Monte Carlo technique with input parameters coming from the analysis of many (858) measured profiles, which are assumed to be a representative sample of possible near-surface velocity profiles. The random generation of velocity profiles has been performed in a few previous studies (e.g. Bernreuter et al, 1986; Anderson et al, 1996) using different approaches than adopted here. Three sets of profiles are used in this study (see Data and Resources Section): those collected and disseminated by David Boore for sites in western North America (http://quake.wr.usgs.gov/ boore/data_online.htm, 277 sites), those collected by Julien Rey for sites in France (43 sites) and those compiled by Guillaume Pousse for Kik-Net strong-motion stations in Japan (538 sites).

These profiles were normalized by dividing the velocity in each layer by the velocity in the surface layer. Then, the normalized velocity slope between two layers was calculated, using the following equation:

$$
\operatorname{slope}(n)=\frac{V_{n+1}^{\prime}-V_{n}^{\prime}}{H_{n}}
$$

where $V_{n}^{\prime}$ is the normalized velocity at layer $n$ and $H_{n}$ the thickness of layer $n$. The 858 profiles lead to 3026 normalized slopes (one for each layer). Then, we extracted the depth and the maximum velocity for each profile, as well as the maximum and minimum thickness of each layer and the surface velocity. The gross characteristics of the profiles collected are summarized in Figures 1 and 2. These figures show that the vast majority of profiles are of soft soil sites with surface shear-wave velocities less than $400 \mathrm{~m} / \mathrm{s}$ and that information is generally only available for the first $100 \mathrm{~m}$ or less with a resolution generally higher than $50 \mathrm{~m}$. Figure 3 shows the computed normalized slopes against depth.

To check that the parameters extracted from the observed profiles were not correlated, we performed a principal component analysis on characteristics such as slope, layer depth, layer thickness or velocity (Table 2). This analysis shows that the slope is poorly correlated with the other variables and, thus, here we neglect the correlation between the slope and other parameters.

[Figure 1 about here.]

[Figure 2 about here.]

[Figure 3 about here.] 
[Table 2 about here.]

The gross characteristics of the profiles are approximatively distributed according to these distributions:

- maximum depth $D$ : log-normal distribution $\left(\phi(x)=\frac{1}{x \beta \sqrt{2 \pi}} \exp \left[-\frac{(\ln (x)-\alpha)^{2}}{2 \beta^{2}}\right]\right.$, where $x$ is a random variable and $\phi(x)$ is the probability density function) with mean $\alpha=4.08$ and standard deviation $\beta=0.70$;

- minimum thickness $H_{m i n}$ : normal distribution $\left(\phi(x)=\frac{1}{\sigma \sqrt{2 \pi}} \exp \left[-\frac{(x-\mu)^{2}}{2 \sigma^{2}}\right]\right)$ with mean $\mu=4.3 \mathrm{~m}$ and standard deviation $\sigma=6.6 \mathrm{~m}$;

- maximum thickness $H_{\max }$ : normal distribution with $\mu=37.6 \mathrm{~m}$ and $\sigma=39.5 \mathrm{~m}$;

- surface velocity $V_{0}$ : log-normal distribution with $\alpha=5.28$ and $\beta=0.49$.

The maximum velocity $V_{\max }$ depends on the depth $D$ of the profile, therefore it was decided to divide the profiles into three groups:

- $D \leq 50 \mathrm{~m}$ : normal distribution of $V_{\max }$ with $\mu=1091.8 \mathrm{~m} / \mathrm{s}$ and $\sigma=519.3 \mathrm{~m} / \mathrm{s}$

- $50<D \leq 100 \mathrm{~m}$ : normal distribution of $V_{\max }$ with $\mu=1141.8 \mathrm{~m} / \mathrm{s}$ and $\sigma=602.0 \mathrm{~m} / \mathrm{s}$

- $D>100 \mathrm{~m}$ : normal distribution of $V_{\max }$ with $\mu=1240.7 \mathrm{~m} / \mathrm{s}$ and $\sigma=648.5 \mathrm{~m} / \mathrm{s}$

Thanks to all these distributions, it was possible to generate stochastic profiles, using the following method:

- random selection of a depth $D$, based on its statistical distribution;

- from the surface to the depth $D$, generation, assuming a uniform distribution, of layers whose thicknesses are constrained by $H_{\min }$ and $H_{\max }$, both parameters being chosen from their statistical distributions;

- random selection of a surface velocity $V_{0}$, based on its statistical distribution;

- for each layer, generation of slope values, based on the empirical distribution (the slope values were found not to closely fit any tested statistical distribution so their empirical distribution was used instead);

- with the slope and the surface velocity $V_{0}$, generation of the velocity of each layer down to depth $D$.

In order to avoid unrealistic results, the profiles were constrained using the following criteria: 
- the velocity of a layer cannot be less than $50 \mathrm{~m} / \mathrm{s}$; and

- the velocity cannot exceed the maximum velocity $V_{\max }$, which is randomly selected from the statistical distribution.

Thus, this method can generate velocity profiles down to depth $D$ (usually between 50 and $200 \mathrm{~m}$ ). However, this approach cannot be used for deeper layers because it is based on shallow profiles and using these values for greater depths leads to unrealistic profiles. It was therefore decided to define much looser constraints on the velocity profile between the depth $D$ and $10 \mathrm{~km}$. First of all, in order to reflect the homogeneity of the medium at these depths, much thicker layers were selected, between 50 and $500 \mathrm{~m}$. The velocity contrast between two layers can be defined by:

$$
R_{n}=\frac{V_{n+1}^{\prime}}{V_{n}^{\prime}}
$$

The values of the impedance factor $R_{n}$ are based on the 858 profiles, leading to a log-normal distribution with parameters $\alpha=0.41$ and $\beta=0.48$. We acknowledge that the methodology used for the deeper layers is based on information extrapolated from the shallow parts of the profile. This assumption is a reasonable way to construct a profile between the upper layers, where statistical results from boreholes can be used, and the lower layers where velocities from crustal structural models are available. Finally, in order to avoid unrealistic results, it was decided to keep only the profiles where:

- the velocity does not exceed $3800 \mathrm{~m} / \mathrm{s}$; and

- the velocity is not less than the value at the depth $D$.

Figure 4 summarizes the procedure that was used to generate the profiles. By visual inspection of numerous simulations, the profiles generated using this approach were seen to show similar characteristics to those in the set of 858 observed profiles. Even though some individual profiles generated by this approach may be unrealistic, the average characteristics of the profiles (which affect amplifications predicted by the one-quarter wavelength method) should match those observed in reality. It is important that there are sufficient constraints in the profile simulation method to exclude physically impossible profiles but on the other hand sufficient freedom must be given so as not to underestimate the width of the confidence limits of the predicted $V_{s, \frac{1}{4}} \mathrm{~s}$.

[Figure 4 about here.] 


\subsection{Constraints on the profiles}

The method above can be used to generate any kind of velocity profile, for any kind of site. Yet, the main goal of this study is to investigate the effects of the quantity of available information on site profiles on the variability of the amplification curve and $V_{s, \frac{1}{4}}$, which could be used within the GMPEs.

We have selected the five following types of information that can be useful to constrain the profiles.

- Surface velocity, $V_{0}$ : this constraint is added in the method above by selecting the same $V_{0}$ for all the simulated profiles.

- Mean velocity down to $30 \mathrm{~m}, V_{s, 30}$ : this data can be obtained with the site class [e.g. Eurocode 8 classification (Comité Européen de Normalisation, 2005)] or approximated using the topographic slope (Wald and Allen, 2007). If the approximate range of $V_{s, 30}$ is known, it is easy then to reject the profiles that do not fall into the desired range.

- The velocity profile down to a certain depth: this can be obtained from geological logs and geotechnical techniques using correlations between SPT and/or soil/rock type and $V_{s}$. To use this constraint, we apply the same procedure as for $V_{0}$, except down to a certain depth. Then the profile is again generated using random parameters. For sites with soil profiles the empirical relations between soil type and shear-wave velocity developed by Ohta and Goto (1978) (their equations VII and VIII) have been used in combination with Table 5.1 of Dowrick (2003) to convert soil/rock descriptions to shear-wave velocities.

- The depth to the bedrock: with this information, we can assume that, below a given depth, the velocity will not be less than a certain value. This constraint may also be added to the model, if available.

- The mean crustal velocities: with these data, it is possible to constrain the velocity at depths of greater than $1 \mathrm{~km}$.

A coefficient of variation of $10 \%$ is applied to $V_{s}$ estimates if they come from geological logs or geotechnical techniques and a coefficient of variation of $25 \%$ is assumed if the $V_{s}$ estimates are deduced from empirical relations between soil type and shear-wave velocity (Ohta and Goto, 1978).

\subsection{Generation of density profiles}

The density does not play a predominant role in the variability of amplification curves. Thus, we used the velocity values to estimate the density using this linear relation (Boore and Joyner, 


$$
\rho\left(V_{s}\right)=2500+\frac{V_{s}-300}{3500-300} \cdot(2800-2500)
$$

Boore and Joyner (1997) state that this relationship is valid for $V_{s}$ between $300 \mathrm{~m} / \mathrm{s}$ and $3.5 \mathrm{~km} / \mathrm{s}$. Some of our profiles include $V_{s}$ outside this range (down to about $100 \mathrm{~m} / \mathrm{s}$ and up to $3.8 \mathrm{~m} / \mathrm{s}$ ) but this should not have a significant impact on the results. For example, for $V_{s}=100 \mathrm{~m} / \mathrm{s}$ Equation 4 gives $\rho=2481 \mathrm{~kg} / \mathrm{m}^{3}$, which is very similar to the recommendation of Boore and Joyner (1997) of $2500 \mathrm{~kg} / \mathrm{m}^{3}$ for $V_{s}<300 \mathrm{~m} / \mathrm{s}$.

\subsection{Generation of amplification curves}

After the simulation of thousands of possible velocity and density profiles, the profiles that do not conform to the constraints applicable for a station are excluded thereby leaving a set of possible profiles for that site. This subset of profiles is then used within the onequarter wavelength approach to estimate the possible site amplifications at that site. The reduction in the uncertainty in the estimated site amplification after applying constraints can then be quantified by comparing these amplifications with those computed using the entire set of generated profiles.

The one-quarter wavelength method also requires the shear-wave velocity and the density in the source region. We chose to take the shear-wave velocity at $10 \mathrm{~km}$ for each profile thereby assuming a hypocentral depth of $10 \mathrm{~km}$. As shown above, the density in the source region can be deduced from the velocity. In other words, the reference is a rock layer having a shear-wave velocity at $10 \mathrm{~km}$ depth. The boundary conditions for both site response methods considered here (quarter-wavelength and Haskell-Thompson) are elastic (also known as transmitting boundary conditions), which is equivalent to outcropping rock reference as used by the geotechnical engineering community.

Near-surface attenuation can be approximated using (Anderson and Hough, 1984): $\exp -\pi \kappa f$, where $\kappa$ is a spectral decay parameter that is commonly assumed to be a constant for a given station although a weak positive dependence on distance has sometimes been observed (e.g. Anderson and Hough, 1984). The amplification $A(f)$ is then multiplied by the near-surface attenuation, approximated using $\kappa$, to obtain an overall amplification. As is standard practice (e.g. Boore and Joyner, 1997) this attenuation filter is applied to the entire frequency range even though $\kappa$ is estimated based on the high-frequency part of Fourier amplitude spectra. In addition, $\kappa$ is assumed to be independent of frequency. In this study, we use a mean value of $\kappa$ for each profile, based on the empirical relationship connecting $V_{s, 30}$ and $\kappa$ presented by Silva et al (1998): $\log \kappa=1.6549-1.0930 \log V_{s, 30}$. In order to model uncertainties in the 
$\kappa \mathrm{s}$ estimated by this equation we have computed a standard deviation of 0.25 from the data points presented in Figure 21 of Silva et al (1998), which has been used to generate a $\kappa$ for each profile. To keep the $\kappa$ s used within a physically-realistic range (e.g. Silva et al, 1998, Figure 21) values less than 0.005 or greater than 0.15 were rejected. The large variability in $\kappa$ estimated from the $V_{s, 30}$ is because near-surface attenuation modeled by $\kappa$ is affected by more than the top $30 \mathrm{~m}$ at a site. In the absence of a better method to estimate $\kappa$ from a given shear-wave velocity profile the large range of $\kappa$ s given by this approach have been accepted even though it could lead to overestimating the uncertainty in the site response for frequencies greater than about $1 \mathrm{~Hz}$, where the effect of attenuation modeled by $\kappa$ becomes important. An alternative would be to use a attenuation $(Q)$ profile, possibly estimated based on empirical relationships between $V_{s}$ and $Q$ (e.g. Barker and Stevens, 1983); however, there are few such correlations and they are also associated with large uncertainties.

\section{Application of proposed approach to RAP stations}

Fumal and Tinsley (1985) present a method and relations for the estimation of one-quarter wavelength velocity for sites in California; a similar technique is applied here for the French RAP sites selected. Recently a RAP working group compiled information on local site conditions at most of the RAP stations (Groupe de Travail RAP, 2007). The type, quality and quantity of information for these stations could be considered representative of the situation for most strong-motion networks, particularly those outside California or Japan, where routine borehole velocity measurements have not been conducted. From the investigated sites we have selected 14 stations that have a range of data available and are from various regions of metropolitan France (see Table 3 for details).

[Table 3 about here.]

Based on the information available for each of the 14 RAP stations (Table 3) stochastic shear-wave velocity profiles were generated using the approach described above. The mean and the 10 and 90th percentile profiles for the 14 stations are displayed in Figure 5. The profiles for stations such as NALS with available detailed soil profiles that can be converted into approximate shear-wave velocities are, as expected, well constrained down to the bottom of the profile. In contrast profiles for stations such as OGMU, with few available constraints on the near-surface shear-wave velocities, show much greater dispersion. There is limited information available to constrain the profiles below the end of the boreholes (at about $50 \mathrm{~m}$ ) and above the start of the available crustal structural models (at 1 or $2 \mathrm{~km}$ ) and, hence, profiles for all stations show a wide dispersion within this depth range. 
[Figure 5 about here.]

Figure 5 shows that some profiles (e.g. NALS, NLIB, NPOR and NPOR) contain velocity inversions, which is explained by negative slopes (Equation 2) as shown in Figure 3. In addition, Figure 3 shows that negative slopes can even be found in deeper layers (e.g. below $100 \mathrm{~m}$ ), which corresponds to the velocity inversions found in some profiles.

Using the stochastic velocity and density profiles, amplification curves for each of the sites were computed using the one-quarter-wavelength technique. Figure 6 shows the mean and 10 and 90th percentile amplification curves for the 14 stations. As is expected the amplifications at stations with measured or, in the case of RAP stations, estimated near-surface velocity profiles are less scattered (e.g. NALS) than those at stations without such constraints (e.g. PYFO). Surprisingly, however, even when detailed soil profiles are available (from which shear-wave velocities can be estimated) site amplifications at high frequencies still show large dispersion. For example, the 10 and 90th percentiles for the amplification at $10 \mathrm{~Hz}$ at NALS are roughly 0.2 and 1.5 (Figure 6), which is surprising since for this site and $10 \mathrm{~Hz}$ the one-quarter wavelength is roughly $5 \mathrm{~m}$ and, hence, it would be thought that a shear-wave velocity profile down to $39 \mathrm{~m}$ would be adequate to precisely define the amplification.

[Figure 6 about here.]

The reason that the amplifications are not more precisely defined when near-surface velocity profiles are available is that near-surface attenuation (here modeled by $\kappa$ ) is not known for these stations and so it is estimated using the equation of Silva et al (1998) with its associated uncertainty. It is this uncertainty that leads to the dispersion in the predicted amplification curves for high frequencies. Figures 7 and 8 show the effect of neglecting the uncertainty in the estimation of $\kappa$ from $V_{s, 30}$ using the equation and data of Silva et al (1998) for two stations with detailed estimated shear-wave velocity profiles: NALS and OGSR. When $\kappa$ is assumed to be precisely known (left-hand graphs) the computed amplification curves are almost exactly known for frequencies greater than roughly $1.5 \mathrm{~Hz}$ but when uncertainty in $\kappa$ is included (righthand graphs) there is considerable uncertainty in the calculated site amplifications. Anderson et al (1996) examine the influence on ground motions of the top $30 \mathrm{~m}$ and they believe that near-surface attenuation is more important than details of the velocity profile for controlling high-frequency ground motions. The results of this study show the need to measure the nearsurface attenuation at strong-motion stations, in addition to near-surface velocities, if it is hoped to calculate accurate site amplifications through modeling of site response.

[Figure 7 about here.] 
[Figure 8 about here.]

Drouet et al (2008) invert ground motions recorded by a selection of RAP stations to retrieve source, path and site parameters for two regions of France: the Pyrenees and the Alps. Within their analysis they included records from seven of the 14 stations studied here. Figure 9 compares the site amplifications and their uncertainties retrieved by Drouet et al (2008) using their inversion technique to those derived using the method followed here. The match between the two sets of amplifications shown in Figure 9 is poor for all of the stations. In general, the method followed here gives higher amplifications than the approach of Drouet et al (2008), except for NROC and OGDH where the amplifications of Drouet et al (2008) are much higher. The amplifications computed by Drouet et al (2008) are relative to an average of sites whose amplification is minimal whereas here the amplifications calculated are absolute with respect to the shear-wave velocity and density at the source. Therefore, the two sets of amplifications are not directly comparable. In addition, the procedure followed here assumes one-dimensional linear site response and therefore it cannot fully model site response at stations affected by two- or three-dimensional effects, such as those in sedimentary valleys (e.g. OGDH and OGSR, which are in the Grenoble basin, and NROC which is on sediments in Nice) whereas the observational method of Drouet et al (2008) may pick up such effects.

[Figure 9 about here.]

Rodriguez-Marek et al (1999) find that the consideration of the depth to bedrock within site classification leads to a reduction in the standard deviation of site amplification estimates. In this study this common observation has been tested for two stations: NALS on shallow sedimentary layers in Nice and OGSR in a deep sedimentary basin in Grenoble. In addition, the decrease in the scattering of the predicted site amplifications through the use of additional constraints (e.g. near-surface shear-wave velocity profile) has been tested. Figure 10 shows four computed site amplification curves (with their confidence limits) for the NALS station when: I) all available data (near-surface profile, depth to bedrock and crustal structure) have been used, II) when the near-surface profile has been replaced by the measured $V_{s, 30}$ and $V_{0}$, III) when the depth to bedrock has been removed as a constraint and IV) when only the $V_{s, 30}$ and the crustal structure have been retained as constraints. Figure 11 shows the four computed amplification curves (with their confidence limits) for the OGSR station for the same four sets of constraints. These two figures show (by comparing the results for cases I and II), as expected, that a near-surface profile helps to narrow the confidence limits of the site amplification curve for frequencies around $1 \mathrm{~Hz}$ but due to the uncertainty in near-surface attenuation the accuracy of high-frequency $(>2 \mathrm{~Hz})$ amplifications is not significantly improved over the case when a 
measured $V_{s, 30}$ is used instead. The inclusion of a depth to bedrock constraint (compare cases II and III) helps reduce the uncertainty in the low frequency $(<1 \mathrm{~Hz})$ amplification curves, confirming the conclusions of previous studies showing the importance of depth to bedrock when computing site response.

[Figure 10 about here.]

[Figure 11 about here.]

It is possible to use our approach to develop generic amplification curves for the site classes defined in earthquake design codes, e.g. Eurocode 8 (EC8) (Comité Européen de Normalisation, $2005)$ in which site classes are based on $V_{s, 30}$ : A, $V_{s, 30}>800 \mathrm{~m} / \mathrm{s} ; \mathrm{B}, 360 \leq V_{s, 30} \leq 800 \mathrm{~m} / \mathrm{s}$; $\mathrm{C}, 180 \leq V_{s, 30}<360 \mathrm{~m} / \mathrm{s}$; and $\mathrm{D}, V_{s, 30}<180 \mathrm{~m} / \mathrm{s}$. The four generic profiles and amplification curves corresponding to EC8 site classes A, B, C and D generated using our approach and the appropriate constraint on $V_{s, 30}$ are presented in Figures 12 and 13, respectively. Cotton et al (2006) present equations for the creation of profiles, based on the generic rock profiles of Boore and Joyner (1997), for a given $V_{s, 30}$ to adjust GMPEs derived for different rock conditions. Our results are compared in Figures 12 and 13 to profiles produced by the approach of Cotton et al (2006) and their corresponding amplifications. These comparisons show that the method developed in this article enables the construction of realistic velocity profiles and are similar to the ones produced by the approach of Cotton et al (2006). In addition, our approach also allows the estimation of the confidence limits of the profiles. The development of generic profiles for each site class enables our approach to be used to evaluate the GMPEs derived using $V_{s, \frac{1}{4}}$ even for sites with little information available on the sub-soil structure. When using these generic profiles (or associated site amplifications) account should be made of the associated accuracy of the $V_{s, \frac{1}{4}}$ estimates so that confidence limits of the predicted ground motions can be correctly assessed.

[Figure 12 about here.]

[Figure 13 about here.]

\section{Regression analysis using $V_{s, \frac{1}{4}} \mathrm{~s}$ of varying accuracies}

The $V_{s, \frac{1}{4}} \mathrm{~s}$ derived using the procedure given above are associated with different variabilities depending on the data available to constrain the velocity and density profiles. Therefore, when using these velocities (or the amplifications) in the derivation of GMPEs weights should be applied to account for their varying accuracies. As discussed by Draper and Smith (1998, 
pp. 223-229) weighted least squares should be applied when the observations have different variances. However, this is not directly comparable to the situation considered here, where the variances (accuracies) of one of the input variables are not the same.

Huo and $\mathrm{Hu}$ (1991) describe an approach to account for errors in magnitude and distance when developing GMPEs and Rhoades (1997) presents a regression method that accounts for differences in variances of magnitudes between earthquakes used to derive GMPEs. The technique of Rhoades (1997) is not directly applicable here since his formulation is based on assuming the errors in magnitude affect the inter-event terms whereas errors in $V_{s, \frac{1}{4}}$ will affect the intra-event terms. In general, regression analysis using measurement-error models (e.g. Fuller, 1987) allows account to be made of errors in the independent variables, such as $V_{s, \frac{1}{4}}$. This type of approach could be used to deal with differences in the variances of the estimates of $V_{s, \frac{1}{4}}$ for each station. Currently there is insufficient strong-motion data available from the RAP to develop robust GMPEs and, therefore, in this article, no regression analysis has been attempted. Nevertheless, Table 4 presents the computed mean $V_{s, \frac{1}{4}} \mathrm{~s}$ and their 10 and 90th percentile confidence limits for the 14 RAP stations and the four EC8 site classes for different spectral periods. Such information would be the basis of the derivation of GMPEs using $V_{s, \frac{1}{4}}$ (Joyner and Fumal, 1984) and a regression procedure to account for the variation in the accuracies of the velocities.

[Table 4 about here.]

\section{Conclusions}

In this article we have estimated the shear-wave velocity profiles and computed the $V_{s, \frac{1}{4}} \mathrm{~s}$ (Joyner and Fumal, 1984) and site amplifications (and their confidence limits) for 14 stations in the RAP strong-motion network of France. In this application most of the available data to constrain the possible shear-wave velocity profiles has been used. To compute a set of realistic shear-wave profiles a stochastic profile simulation technique was developed based on statistical descriptions of the characteristics of 858 measured profiles from western North America, France and Japan. The advantage of this is that when the computed $V_{s, \frac{1}{4}} \mathrm{~s}$ (or site amplifications) are used to develop GMPEs the common assumption of equal quality and quantity of site information is no longer required. Data from stations should be weighted within the regression analysis based on the accuracy of the computed $V_{s, \frac{1}{4}}$ s. Such a weighted regression analysis is planned for a future extension of this study.

This proposed method, therefore, has the ability to incorporate all the available information on local site conditions into the derivation of ground motion estimation equations rather 
than, as is done at present, be forced to default to a crude site classification scheme because of a lack of information for some stations. It accounts for the fact that the quality of local site information varies significantly between stations - a heterogeneity that is not normally considered when deriving GMPEs. This method will not significantly improve site-specific earthquake-specific site response estimates because, as Boore (2004) shows, these estimates require detailed knowledge of the source and the three-dimensional structure beneath the station. However, it should improve overall estimates of average site response and consequently empirical ground-motion predictions.

From this study a number of important conclusions on the estimation of site amplifications based on modeling using geophysical data can be made. It has been demonstrated that precise amplification estimates at high frequencies rely on accurate estimates of near-surface attenuation (i.e. $\kappa$ or $Q$ ), which is not usually measured, as well as near-surface shear-wave velocity. In addition, the application of depth to bedrock constraints can improve the accuracy of amplification curves for frequencies around $1 \mathrm{~Hz}$.

The presented technique, however, has some drawbacks. Firstly, as pointed out by one of the reviewers (Adrian Rodriguez-Marek), the use of the surface velocity $V_{0}$ may pose problems due to the presence of an anthropogenic shallow layer biasing $V_{0}$ and the fact that the variability of this velocity might be larger than the one computed from an average velocity over a certain depth. Secondly, by using the one-quarter wavelength approach we assume one-dimensional linear site response, which is a common assumption when deriving empirical GMPEs. However, this assumption means that predicted site amplifications derived using this approach are unlikely to be accurate for sites with strong two- or three-dimensional site effects (e.g. those stations in sedimentary basins) or for sites where nonlinear soil response is possible for large amplitude ground motions. Since nonlinear soil response only becomes apparent for peak ground accelerations greater than 0.1-0.2 g (e.g. Beresnev and Wen, 1996) site amplification for the majority of records should be accurately predicted despite neglecting nonlinearity.

The second disadvantage of the proposed approach is that it does not currently make use of site response information coming from analysis of recorded earthquakes or ambient vibrations, such as horizontal/vertical (H/V) spectral ratios (e.g. Duval et al, 2001; Fukushima et al, 2007). This information could be useful in constraining the shear-wave velocity profiles at depths beyond the end of information coming from boreholes. The disadvantage of not making use of this information has been demonstrated here by the generally poor match between computed site amplifications and those presented by Drouet et al (2008) for seven common stations. However, it should be possible to make use of this information by conducting full one-dimensional site 
response analysis (rather than making the one-quarter wavelength approximation) for the set of generated profiles and then rejecting those profiles whose site response does not match the observations coming from recorded data. A benefit of the one-quarter wavelength approach, however, is that the one-quarter wavelength velocities $\left(V_{s, \frac{1}{4}}\right)$ obtained from the profiles can be easily included within the functional form of the derived GMPEs through the addition of a term: $k \log \left(V_{s, \frac{1}{4}} / V_{0}\right)$, where $k$ and $V_{0}$ are coefficients to be found by regression analysis, which is based on the physics of site response (Joyner and Fumal, 1984). Using the average velocities down to a depth of one-quarter wavelength neglects the effect of variation in the velocity structure below this depth, which at high frequencies would mean neglecting variations below a few tens of metres.

As an example of the benefit of full one-dimensional site response analysis when making use of results of $\mathrm{H} / \mathrm{V}$ spectral ratios (or other estimates of the site response) to better constrain profiles Figure 14 compares the amplification curves computed using the Haskell-Thompson approach with those estimated using the one-quarter wavelength approximation for the OGDH station in the Grenoble basin. This comparison shows that the Haskell-Thompson approach predicts this site's fundamental frequency (at about $0.2 \mathrm{~Hz}$ ) whereas the one-quarter wavelength approximation does not. Consequently if estimates of a site's fundamental frequency are available from observational data, such as $\mathrm{H} / \mathrm{V}$ spectral analysis, the one-quarter wavelength approximation would not make use of this information. The OGDH amplification curve for this station derived using the Haskell-Thompson approach (Figure 14) compares well with the amplifications estimated by Drouet et al (2008) (Figure 9). This example demonstrates the final principal disadvantage of basing our approach on the one-quarter wavelength assumption, i.e. the site response at stations underlain by large impedance contrasts, with consequently site responses featuring multi-reflections, could be poorly characterized. Nevertheless, we prefer the one-quarter wavelength approach for our procedure due to the ease with which the $V_{s, \frac{1}{4}} \mathrm{~s}$ can be introduced into empirical GMPEs.

[Figure 14 about here.]

\section{$7 \quad$ Data and Resources}

- Compilation of shear-wave velocity profiles for western North American sites by David M. Boore (http://quake.wr.usgs.gov/ boore/data_online.htm, last accessed March $32008)$.

- Compilation of shear-wave velocity profiles for French sites by Julien Rey. They cannot be released to the public. 
- Compilation of shear-wave velocity profiles for Kik-Net sites by Guillaume Pousse.

- All other data came from published sources listed in the references.

\section{Acknowledgments}

This study was funded by BRGM research and public service projects and a grant from the Réseau Accélérometrique Permanent (RAP) of France. We thank: the RAP working group on geotechnical site characterization for their data collection tasks and Philippe Guéguen for providing this information; Julien Rey, Guillaume Pousse and David Boore for providing their compilations of shear-wave velocity profiles; Sylvette Bonnefoy-Claudet for advice and for providing a copy of Vallon (1999); and Stéphane Drouet for sending us the numerical values of his amplification curves. Finally, we thank Adrian Rodriguez-Marek, an anonymous reviewer and associate editor, Julian Bommer, for their careful and detailed reviews, which led to significant improvements to this article.

\section{References}

Abercrombie RE (1997) Near-surface attenuation and site effects from comparison of surface and deep borehole recordings. Bulletin of the Seismological Society of America 87(3):731-744

Abrahamson N, Silva W (2008) Summary of the Abrahamson \& Silva NGA ground-motion relations. Earthquake Spectra 24(1):67-97, DOI 10.1193/1.2924360

Ambraseys NN (1995) The prediction of earthquake peak ground acceleration in Europe. Earthquake Engineering and Structural Dynamics 24(4):467-490

Anderson JG, Hough SE (1984) A model for the shape of the Fourier amplitude spectrum of acceleration at high frequencies. Bulletin of the Seismological Society of America 74(5):19691993

Anderson JG, Lee Y, Zeng Y, Day S (1996) Control of strong motion by the upper 30 meters. Bulletin of the Seismological Society of America 86(6):1749-1759

Andrus RD, Piratheepan P, Ellis BS, Zhang J, Juang CH (2004) Comparing liquefaction evaluation methods using penetration- $V_{S}$ relationships. Soil Dynamics and Earthquake Engineering 24(9-10):713-721

Bard PY, Duval AM, Bertrand E, Vassiliades JF, Vidal S, Foin P, Guéguen P, Thibault C, Guyet B, Dunand F, Bonnefoy-Claudet S, Méneroud JP, Vettori G (2005) Le risque sismique 
á Nice: Rapport méthodologique, résultats et perspectives opérationnelles. Final GEM-GEP report, LCPC, CGPC, METATTM, MEDD, CANCA, pp. 52

Barker TG, Stevens JL (1983) Shallow shear wave velocity and $Q$ structures at the El Centro strong motion accelerograph array. Geophysical Research Letters 10(9):853-856

Beresnev IA, Wen KL (1996) Nonlinear soil response - a reality? Bulletin of the Seismological Society of America 86(6):1964-1978

Berge-Thierry C, Cotton F, Scotti O, Griot-Pommera DA, Fukushima Y (2003) New empirical response spectral attenuation laws for moderate European earthquakes. Journal of Earthquake Engineering 7(2):193-222

Bernreuter DL, Chen JC, Savy JB (1986) A methodology to correct for the effect of the local site's characteristics in seismic hazard analysis. In: Proceedings of the Third U.S. National Conference on Earthquake Engineering, vol I, pp 245-255

Boore DM (2003) Simulation of ground motion using the stochastic method. Pure and Applied Geophysics 160(3-4):635-676, DOI 10.1007/PL00012553

Boore DM (2004) Can site response be predicted? Journal of Earthquake Engineering 8(Special issue 1$): 1-42$

Boore DM (2005) SMSIM - Fortran programs for simulating ground motions from earthquakes: Version 2.3 - A revision of OFR 96-80-A. Open-File Report 00-509, United States Geological Survey, modified version, describing the program as of 15 August 2005 (Version $2.30)$.

Boore DM, Atkinson GM (2007) Boore-Atkinson NGA ground motion relations for the geometric mean horizontal component of peak and spectral ground motion parameters. PEER Report 2007/01, Pacific Earthquake Engineering Research Center, College of Engineering, University of California, Berkeley

Boore DM, Atkinson GM (2008) Ground-motion prediction equations for the average horizontal component of PGA, PGV, and 5\%-damped PSA at spectral periods between $0.01 \mathrm{~s}$ and $10.0 \mathrm{~s}$. Earthquake Spectra 24(1):99-138, DOI 10.1193/1.2830434

Boore DM, Joyner WB (1991) Estimation of ground motion at deep-soil sites in eastern North America. Bulletin of the Seismological Society of America 81(6):2167-2185

Boore DM, Joyner WB (1997) Site amplifications for generic rock sites. Bulletin of the Seismological Society of America 87(2):327-341 
Borcherdt RD (1994) Estimates of site-dependent response spectra for design (methodology and justification). Earthquake Spectra 10(4):617-653

BRGM (2008a) Carte géologique imprimée. URL http://infoterre.brgm.fr/

BRGM (2008b) La Banque du Sous-Sol. URL http://infoterre.brgm.fr/

Campbell KW, Bozorgnia Y (2008) NGA ground motion model for the geometric mean horizontal component of PGA, PGV, PGD and 5\% damped linear elastic response spectra for periods ranging from 0.01 to $10 \mathrm{~s}$. Earthquake Spectra 24(1):139-171, DOI 10.1193/1.2857546

Chandler AM, Lam NTK, Tsang HH (2005) Shear wave velocity modelling in crustal rock for seismic hazard analysis. Soil Dynamics and Earthquake Engineering 25(2):167-185

Chandler AM, Lam NTK, Tsang HH (2006) Near-surface attenuation modelling based on rock shear-wave velocity profile. Soil Dynamics and Earthquake Engineering 26(11):1004-1014

Chiou BSJ, Youngs RR (2008) An NGA model for the average horizontal component of peak ground motion and response spectra. Earthquake Spectra 24(1):173-215, DOI $10.1193 / 1.2894832$

Comité Européen de Normalisation (2005) Eurocode 8, Design of structures for earthquake resistance - part 1: General rules, seismic actions and rules for buildings. European Standard NF EN 1998-1

Cotton F, Scherbaum F, Bommer JJ, Bungum H (2006) Criteria for selecting and adjusting ground-motion models for specific target regions: Application to central Europe and rock sites. Journal of Seismology 10(2):137-156, DOI 10.1007/s10950-005-9006-7

Douglas J (2003) Earthquake ground motion estimation using strong-motion records: A review of equations for the estimation of peak ground acceleration and response spectral ordinates. Earth-Science Reviews 61(1-2):43-104

Dowrick DJ (2003) Earthquake Risk Reduction. John Wiley \& Sons Ltd, Chichester, United Kingdom

Draper NR, Smith H (1998) Applied Regression Analysis, 3rd edn. John Wiley \& Sons

Drouet S, Chevrot S, Cotton F, Souriau A (2008) Simultaneous inversion of source spectra, attenuation parameters, and site responses: Application to the data of the French Accelerometric Network. Bulletin of the Seismological Society of America 98(1):198-219, DOI $10.1785 / 0120060215$ 
Duval AM, Bard PY, Le Brun B, Lacave-Lachet C, Riepl J, Hatzfeld D (2001) H/V technique for site response analysis synthesis of data from various surveys. Bollettino di Geofisica Teorica ed Applicata 42(3-4):267-280

European-Mediterranean Seismological Centre (2007) Euro-Med accelerometric networks in the Euro-Med region. URL http://www.emsc-csem.org/index.php?page=projects\&sub=accelero

Field EH (2000) A modified ground-motion attenuation relationship for southern California that accounts for detailed site classification and a basin-depth effect. Bulletin of the Seismological Society of America 90(6B):S209-S221

Fukushima Y, Bonilla LF, Scotti O, Douglas J (2007) Site classification using horizontalto-vertical response spectral ratios and its impact when deriving empirical ground motion prediction equations. Journal of Earthquake Engineering 11(5):712-724, DOI $10.1080 / 13632460701457116$

Fuller WA (1987) Measurement Error Models. John Wiley \& Sons, New York, USA

Fumal TE, Tinsley JC (1985) Mapping shear-wave velocities of near-surface geologic materials. In: Evaluating Earthquake Hazards in the Los Angeles Region - An Earth Science Perspective, no. 1360 in U.S. Geological Survey Professional Paper, United States Government Printing Office, Washington, pp 127-149

Groupe de Travail RAP (2007) Reconnaissance géotechnique des stations du RAP: Phase pilote. Tech. rep., Réseau Accélérometrique Permanent, UMR LGIT, BRGM, CETE Nice, IRSN, IRD, LCPC

Hasancebi N, Ulusay R (2007) Empirical correlations between shear wave velocity and penetration resistance for ground shaking assessments. Bulletin of Engineering Geology and the Environment 66(2):203-213, DOI 10.1007/s10064-006-0063-0

Huo J, Hu Y (1991) Attenuation laws considering the randomness of magnitude and distance. Earthquake Research in China 5(1):17-36

Idriss IM (2008) An NGA empirical model for estimating the horizontal spectral values generated by shallow crustal earthquakes. Earthquake Spectra 24(1):217-242, DOI $10.1193 / 1.2924362$

Joyner WB, Fumal TE (1984) Use of measured shear-wave velocity for predicting geologic site effects on strong ground motion. In: Proceedings of Eighth World Conference on Earthquake Engineering, vol II, pp 777-783 
Joyner WB, Warrick RE, Fumal TE (1981) The effect of quaternary alluvium on strong ground motion in the Coyote Lake, California, earthquake of 1979. Bulletin of the Seismological Society of America 71(4):1333-1349

Kamiyama M, Yanagisawa E (1986) A statisical model for estimating response spectra of strong earthquake ground motions with emphasis on local soil conditions. Soils and Foundations 26(2):16-32

Laske G, Dziewonski A, Masters G (2005) The Reference Earth Model website. On Internet at: http://mahi.ucsd.edu/Gabi/rem.html

Ohta Y, Goto N (1978) Empirical shear wave velocity equations in terms of characteristic soil indexes. Earthquake Engineering and Structural Dynamics 6:167-187

Parolai S, Bormann P, Milkereit C (2002) New relationship between $V_{s}$, thickness of sediments, and resonance frequency calculated by the $\mathrm{H} / \mathrm{V}$ ratio of seismic noise for the Cologne area (Germany). Bulletin of the Seismological Society of America 92(6):2521-2527

Rhoades DA (1997) Estimation of attenuation relations for strong-motion data allowing for individual earthquake magnitude uncertainties. Bulletin of the Seismological Society of America $87(6): 1674-1678$

Rodriguez-Marek A, Bray JD, Abrahamson N (1999) Task 3: Characterization of site response general site categories. PEER Report 1999/03, Pacific Earthquake Engineering Research Center, College of Engineering, University of California, Berkeley

ROSRINE (2008) ResOlution of Site Response Issues from the Northridge Earthquake. URL http://gees.usc.edu/ROSRINE/

Silva W, Darragh R, Gregor N, Martin G, Abrahamson N, Kircher C (1998) Reassessment of site coefficients and near-fault factors for building code provisions. Tech. Rep. Program Element II: 98-HQ-GR-1010, Pacific Engineering and Analysis, El Cerrito, USA

Souriau A, Granet M (1995) A tomographic study of the lithosphere beneath the Pyrenees from local and teleseismic data. Journal of Geophysical Research 100(B9):18,117-18,134

Souriau A, Roullé A, Ponsolles C (2007) Site effects in the city of Lourdes, France, from H/V measurements: Implications for seismic-risk evaluation. Bulletin of the Seismological Society of America 97(6):2118-2136, DOI 10.1785/0120060224 
Spudich P, Joyner WB, Lindh AG, Boore DM, Margaris BM, Fletcher JB (1999) SEA99: A revised ground motion prediction relation for use in extensional tectonic regimes. Bulletin of the Seismological Society of America 89(5):1156-1170

Vallon M (1999) Estimation de l'épaisseur d'alluvions quaternaires dans la cuvette grenobloise par inversion des anomalies gravimétriques. Tech. rep., Université Joseph Fourier \& Laboratoire de Glaciologie et Géophysique de l'Environnement du C.N.R.S., Grenoble, France, in French

Wald DJ, Allen TI (2007) Topographic slope as a proxy for seismic site conditions and amplification. Bulletin of the Seismological Society of America 97(5):1379-1395, DOI $10.1785 / 0120060267$

Wei BZ, Pezeshk S, Chang TS, Hall KH, Liu HP (1996) An empirical method to estimate shear wave velocity of soils in the New Madrid seismic zone. Soil Dynamics and Earthquake Engineering 15(6):399-408

Wills CJ, Petersen M, Bryant WA, Reichle M, Saucedo GJ, Tan S, Taylor G, Treiman J (2000) A site-conditions map for California based on geology and shear-wave velocity. Bulletin of the Seismological Society of America 90(6B):S187-S208 


\section{List of Figures}

1 Histograms showing the characteristics of the 858 shear-wave velocity profiles used to derive statistics for the generation of stochastic profiles. . . . . . . . . .

2 Maximum shear-wave velocity within the profile against depth of profile for the 858 shear-wave velocity profiles. This graph only goes up to $300 \mathrm{~m}$ due to a limited number of deeper profiles. . . . . . . . . . . . . . .

3 Normalized slopes against depth for the 858 shear-wave velocity profiles. This graph only goes up to $200 \mathrm{~m}$ due to few slopes from greater depths. . . . . . . .

4 Summary of method used to generate the velocity profiles, using various types of information depending on the depth. . . . . . . . . . . .

$5 \quad$ Estimated mean shear-wave velocity profiles for the 14 selected RAP stations (solid lines) and their 10 and 90\% confidence limits (dashed lines) using the method developed within this article. . . . . . . . . . . . . . .

6 Mean site amplification curves (solid lines) and their 10 and 90\% confidence limits estimated for the 14 RAP stations using the shear-wave velocity profiles derived in this study and presented in Figure 5. . . . . . . . . . . . . . .

7 Comparison between the computed mean site amplifications (solid lines) and their 10 and $90 \%$ confidence limits (dashed lines) for the NALS station when the uncertainty in $\kappa$ estimated from the $V_{s, 30}$ is neglected (left-hand figure) and when it is considered (right-hand figure) . . . . . . . . . . . .

8 Comparison between the computed mean site amplifications (solid lines) and their 10 and $90 \%$ confidence limits (dashed lines) for the OGSR station when the uncertainty in $\kappa$ estimated from the $V_{s, 30}$ is neglected (left-hand figure) and when it is considered (right-hand figure) . . . . . . . . . . . . . . .

9 Comparison between the site amplification curves computed in this study and their 10 and 90\% confidence limits (solid lines) and the site amplifications (and their $\pm 1.28 \sigma$ confidence limits, corresponding to the 10 and $90 \%$ confidence limits for a normal distribution) computed by source-path-site inversion by Drouet et al (2008) (dashed lines) for the seven common stations. Note that the amplifications derived by Drouet et al. (2008) are relative to an average of sites whose amplification is minimal whereas the amplifications calculated in this study are absolute with respect to the shear-wave velocity and density at the source. . . . 
10 Mean site amplification curves for the NALS station (solid lines) and their 10 and 90\% confidence limits (dashed lines) for four sets of constraints: I) near-surface shear-wave velocity profile, depth to bedrock and crustal structure; II) $V_{0}, V_{s, 30}$, depth to bedrock and crustal structure; III) $V_{0}, V_{s, 30}$ and crustal structure; and

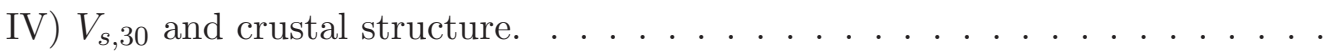

11 Mean site amplification curves for the OGSR station (solid lines) and their 10 and $90 \%$ confidence limits (dashed lines) for four sets of constraints: I) nearsurface shear-wave velocity profile, depth to bedrock and crustal structure; II) $V_{0}, V_{s, 30}$, depth to bedrock and crustal structure; III) $V_{0}, V_{s, 30}$ and crustal structure; and IV) $V_{s, 30}$ and crustal structure. . . . . . . . . .

12 Generated velocity profiles for four EC8 site classes and their 10 and 90\% confidence limits (dashed lines). The grey solid line represents the velocity profile given by the generic model of Cotton et al (2006) based on $V_{s, 30} \ldots \ldots$. . . .

13 Amplification curves for four EC8 site classes, and their 10 and 90\% confidence limits (dashed lines). The grey solid line represents the amplification curve that was computed using the velocity profile given by the generic model of Cotton et al (2006) based on $V_{s, 30} \ldots \ldots \ldots \ldots \ldots \ldots \ldots$

14 Comparison between the mean amplification curve and its 10 and $90 \%$ confidence limits computed using the one-quarter wavelength method (thick lines) and the mean amplification curve and its 10 and 90\% confidence limits computed using the Haskell-Thompson method (thin lines) for the OGDH station. The profiles simulated using the Monte Carlo technique developed in this article are used for both computations. . . . . . . . . . . . . . . . . . . . 
Figure 1: Histograms showing the characteristics of the 858 shear-wave velocity profiles used to derive statistics for the generation of stochastic profiles.
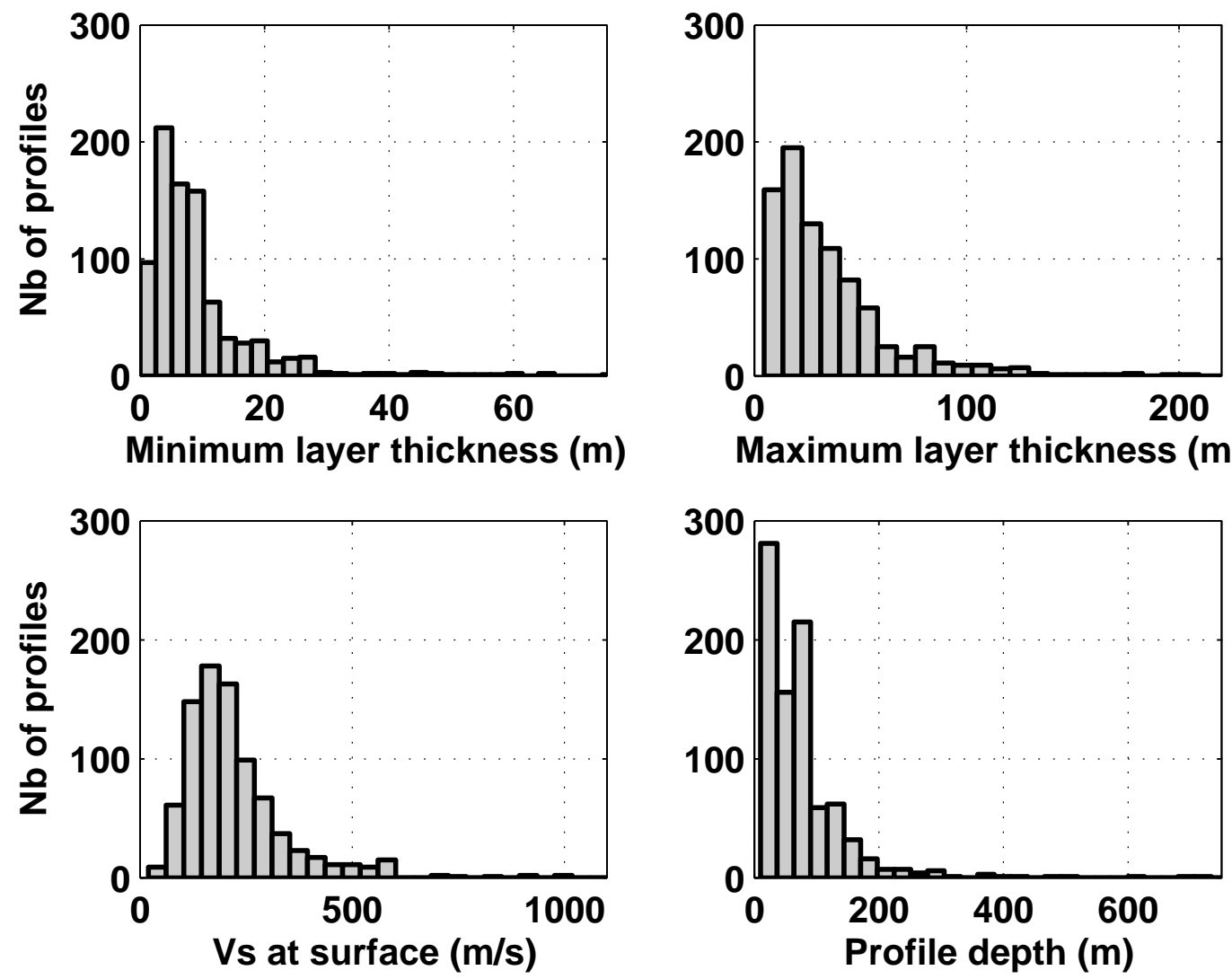
Figure 2: Maximum shear-wave velocity within the profile against depth of profile for the 858 shear-wave velocity profiles. This graph only goes up to $300 \mathrm{~m}$ due to a limited number of deeper profiles.

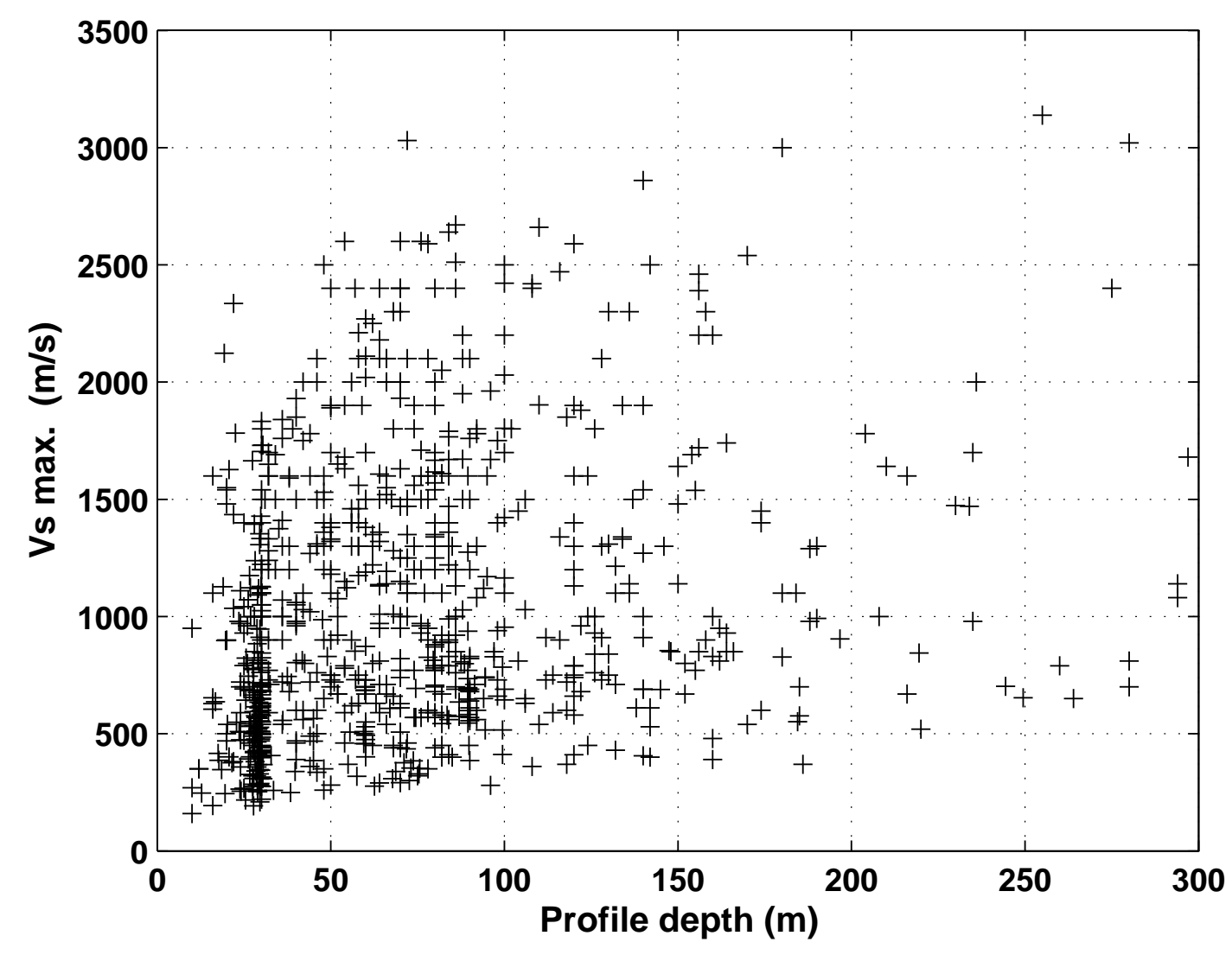


Figure 3: Normalized slopes against depth for the 858 shear-wave velocity profiles. This graph only goes up to $200 \mathrm{~m}$ due to few slopes from greater depths.

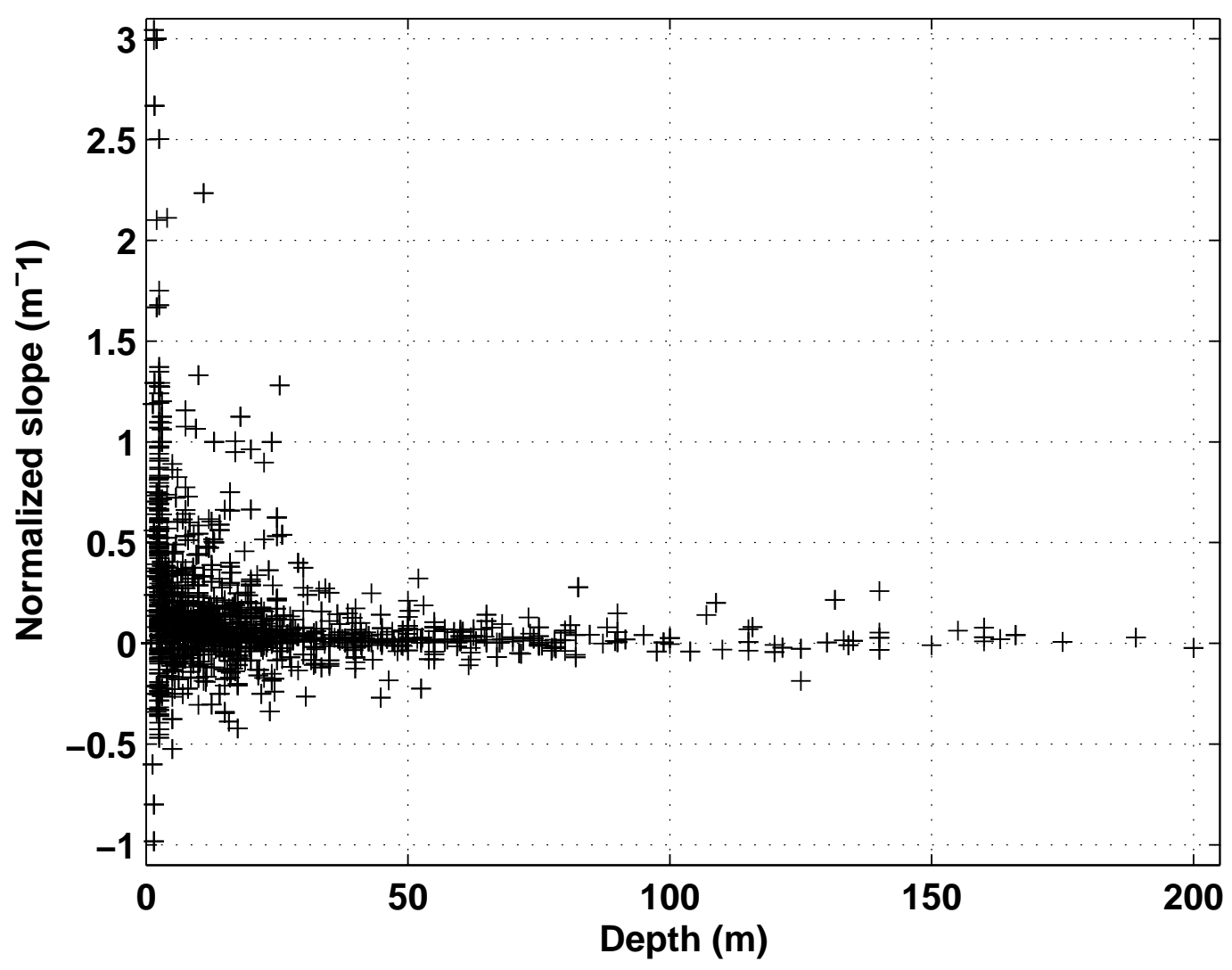


Figure 4: Summary of method used to generate the velocity profiles, using various types of information depending on the depth.

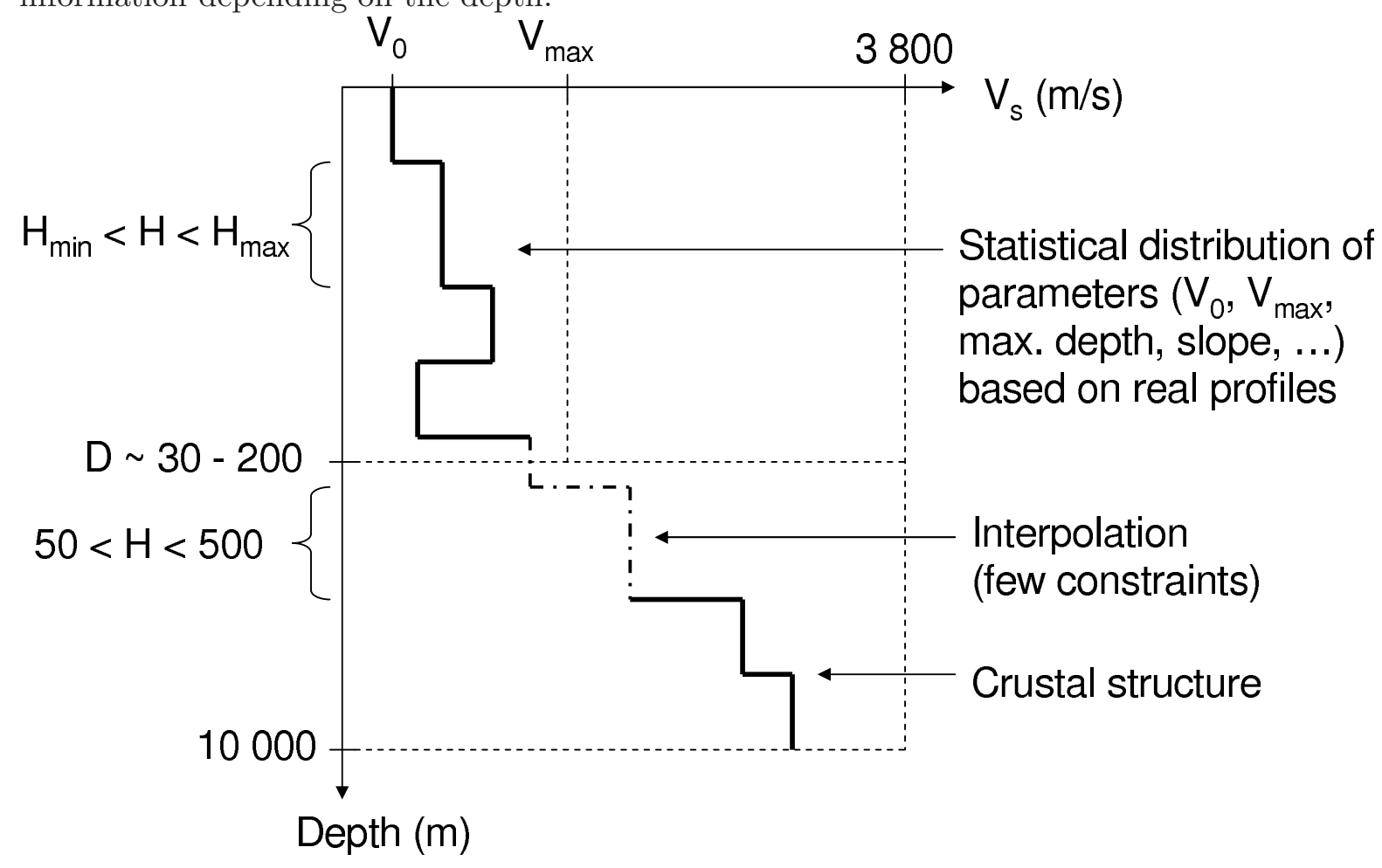


Figure 5: Estimated mean shear-wave velocity profiles for the 14 selected RAP stations (solid lines) and their 10 and 90\% confidence limits (dashed lines) using the method developed within this article.
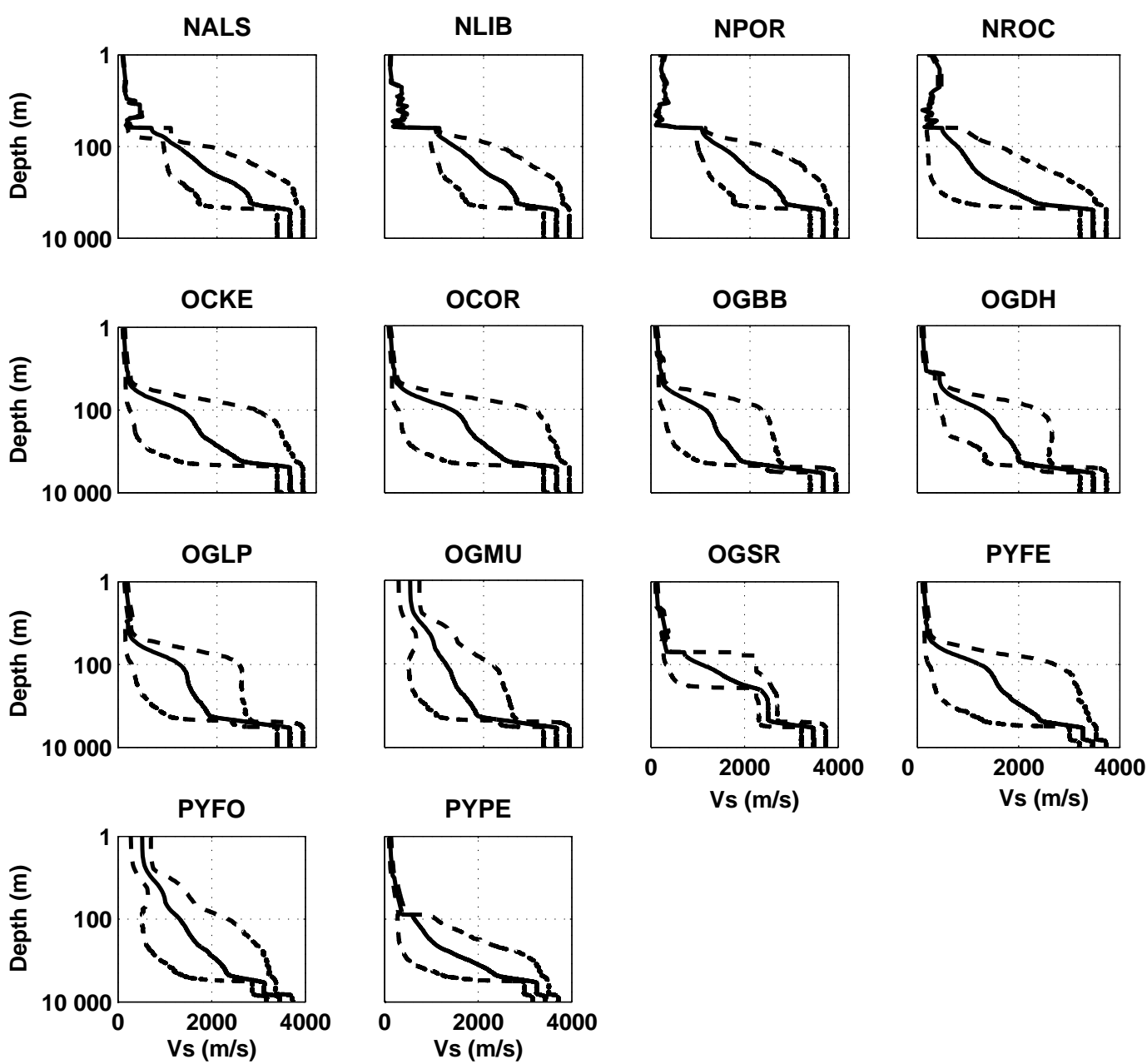
Figure 6: Mean site amplification curves (solid lines) and their 10 and $90 \%$ confidence limits estimated for the 14 RAP stations using the shear-wave velocity profiles derived in this study and presented in Figure 5.
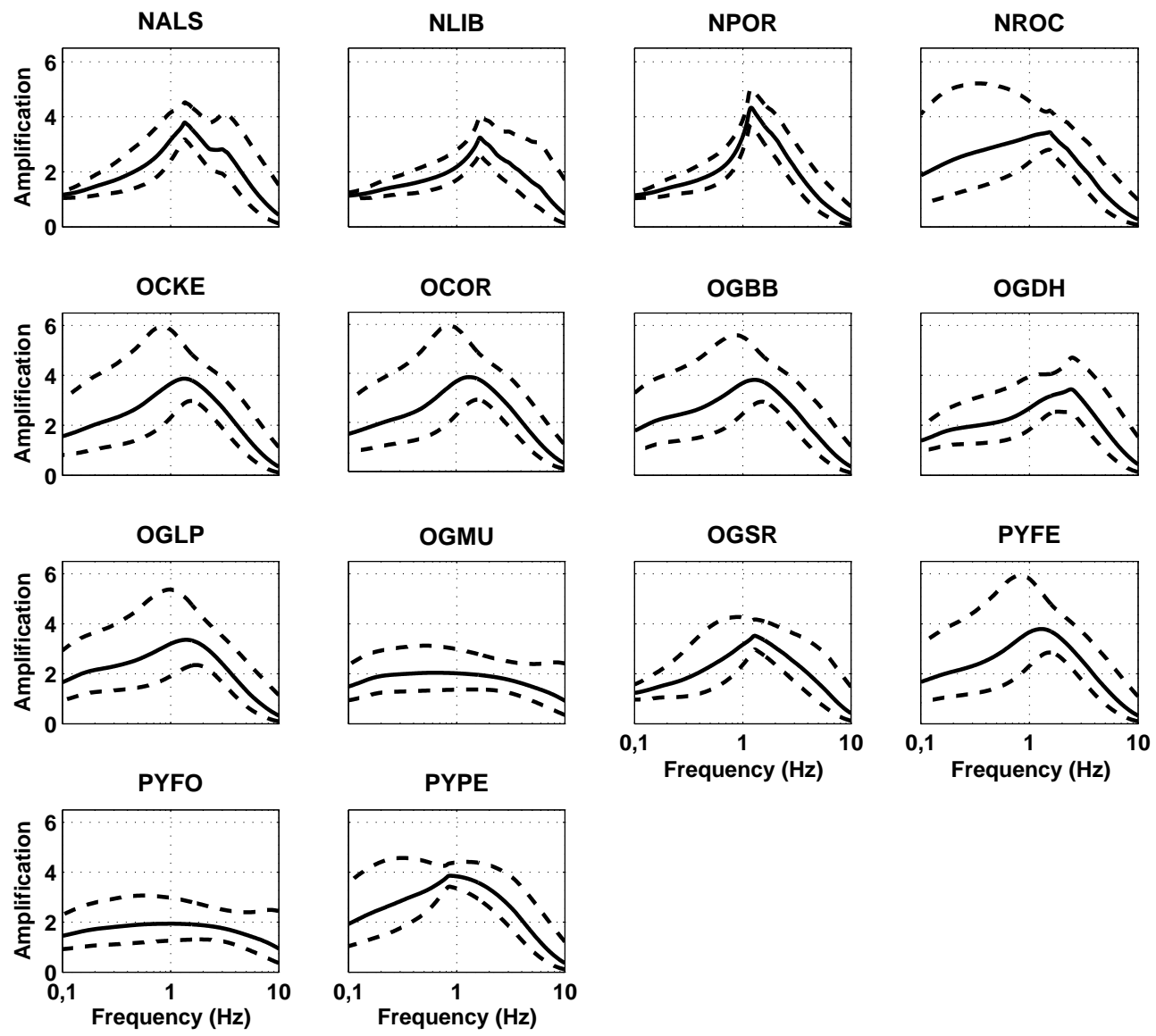
Figure 7: Comparison between the computed mean site amplifications (solid lines) and their 10 and $90 \%$ confidence limits (dashed lines) for the NALS station when the uncertainty in $\kappa$ estimated from the $V_{s, 30}$ is neglected (left-hand figure) and when it is considered (right-hand figure).
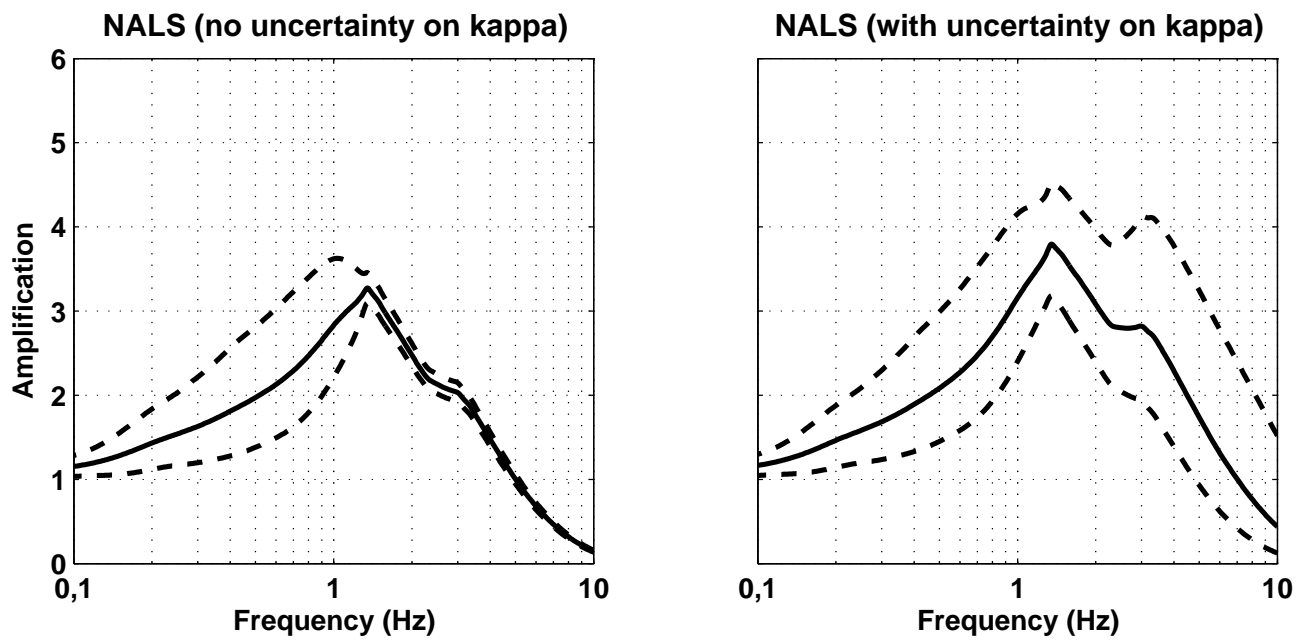
Figure 8: Comparison between the computed mean site amplifications (solid lines) and their 10 and $90 \%$ confidence limits (dashed lines) for the OGSR station when the uncertainty in $\kappa$ estimated from the $V_{s, 30}$ is neglected (left-hand figure) and when it is considered (right-hand figure).
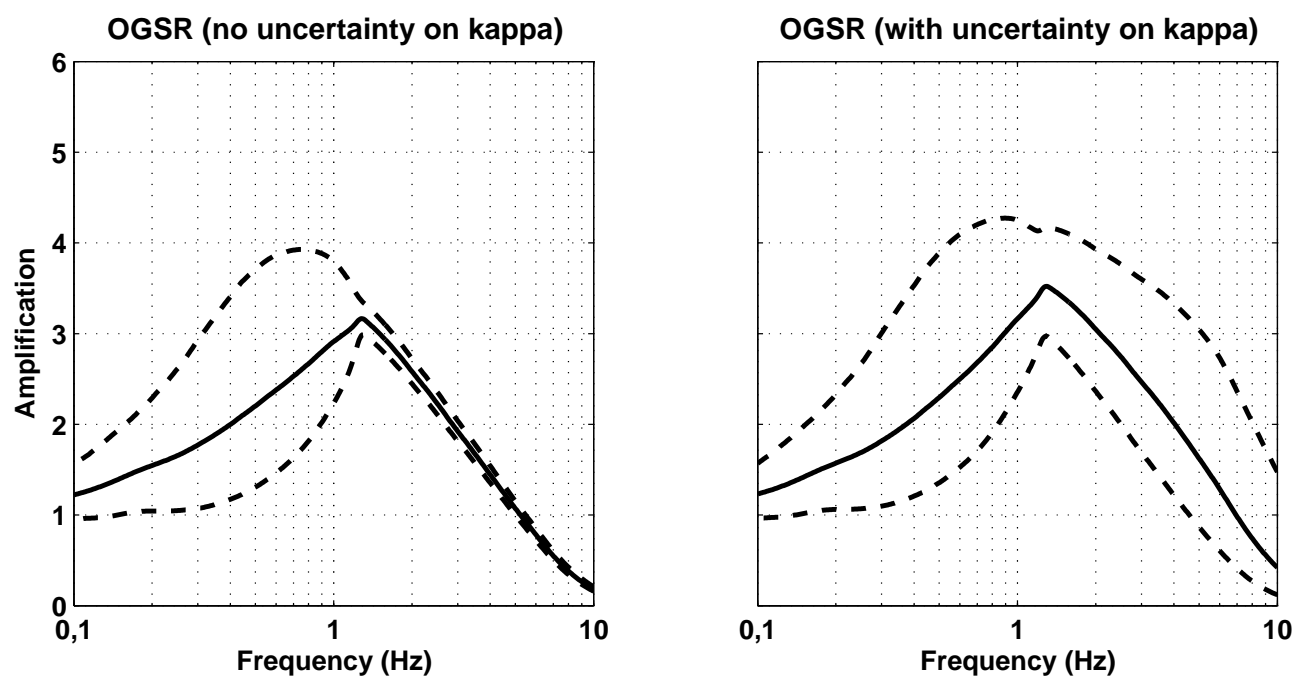
Figure 9: Comparison between the site amplification curves computed in this study and their 10 and $90 \%$ confidence limits (solid lines) and the site amplifications (and their $\pm 1.28 \sigma$ confidence limits, corresponding to the 10 and $90 \%$ confidence limits for a normal distribution) computed by source-path-site inversion by Drouet et al (2008) (dashed lines) for the seven common stations. Note that the amplifications derived by Drouet et al. (2008) are relative to an average of sites whose amplification is minimal whereas the amplifications calculated in this study are absolute with respect to the shear-wave velocity and density at the source.
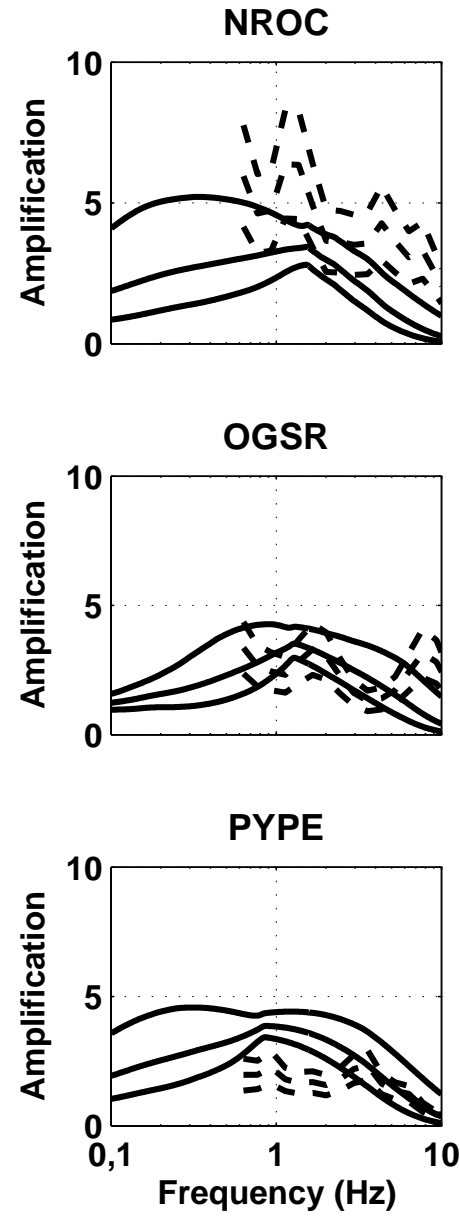

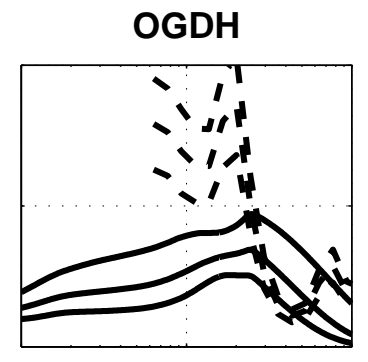

PYFE

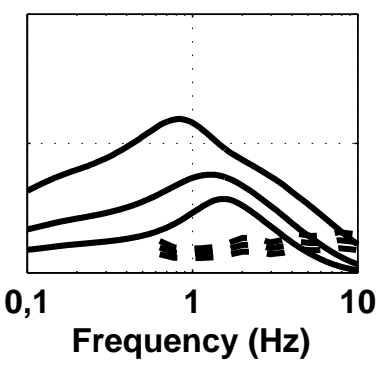

OGMU

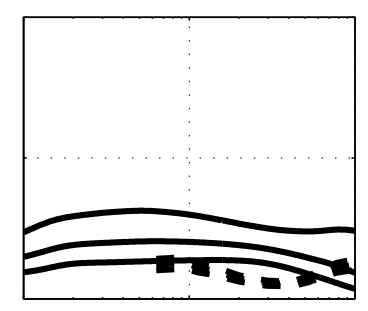

PYFO

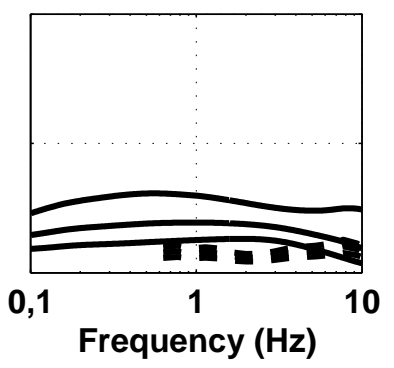


Figure 10: Mean site amplification curves for the NALS station (solid lines) and their 10 and $90 \%$ confidence limits (dashed lines) for four sets of constraints: I) near-surface shear-wave velocity profile, depth to bedrock and crustal structure; II) $V_{0}, V_{s, 30}$, depth to bedrock and crustal structure; III) $V_{0}, V_{s, 30}$ and crustal structure; and IV) $V_{s, 30}$ and crustal structure.
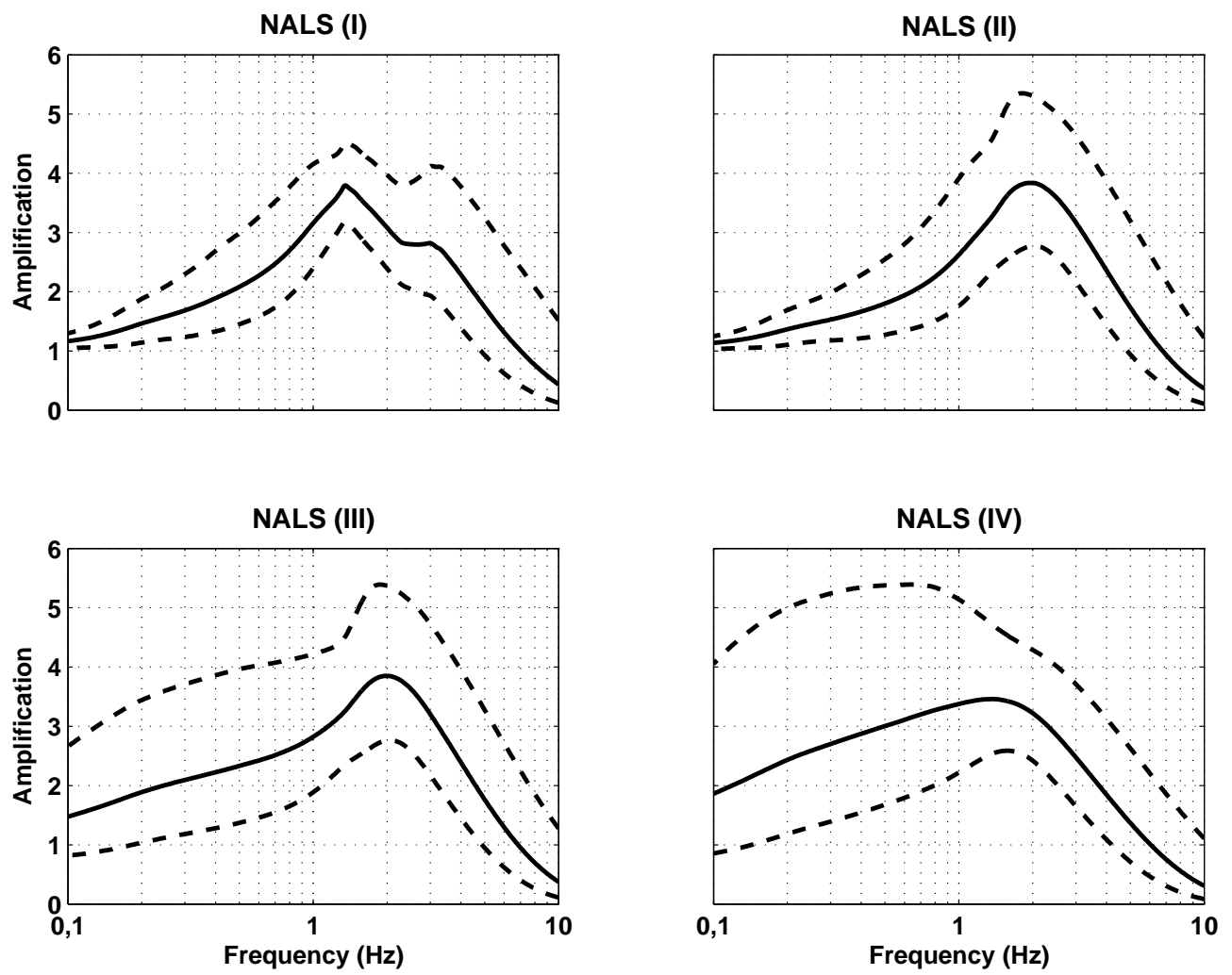
Figure 11: Mean site amplification curves for the OGSR station (solid lines) and their 10 and $90 \%$ confidence limits (dashed lines) for four sets of constraints: I) near-surface shear-wave velocity profile, depth to bedrock and crustal structure; II) $V_{0}, V_{s, 30}$, depth to bedrock and crustal structure; III) $V_{0}, V_{s, 30}$ and crustal structure; and IV) $V_{s, 30}$ and crustal structure.
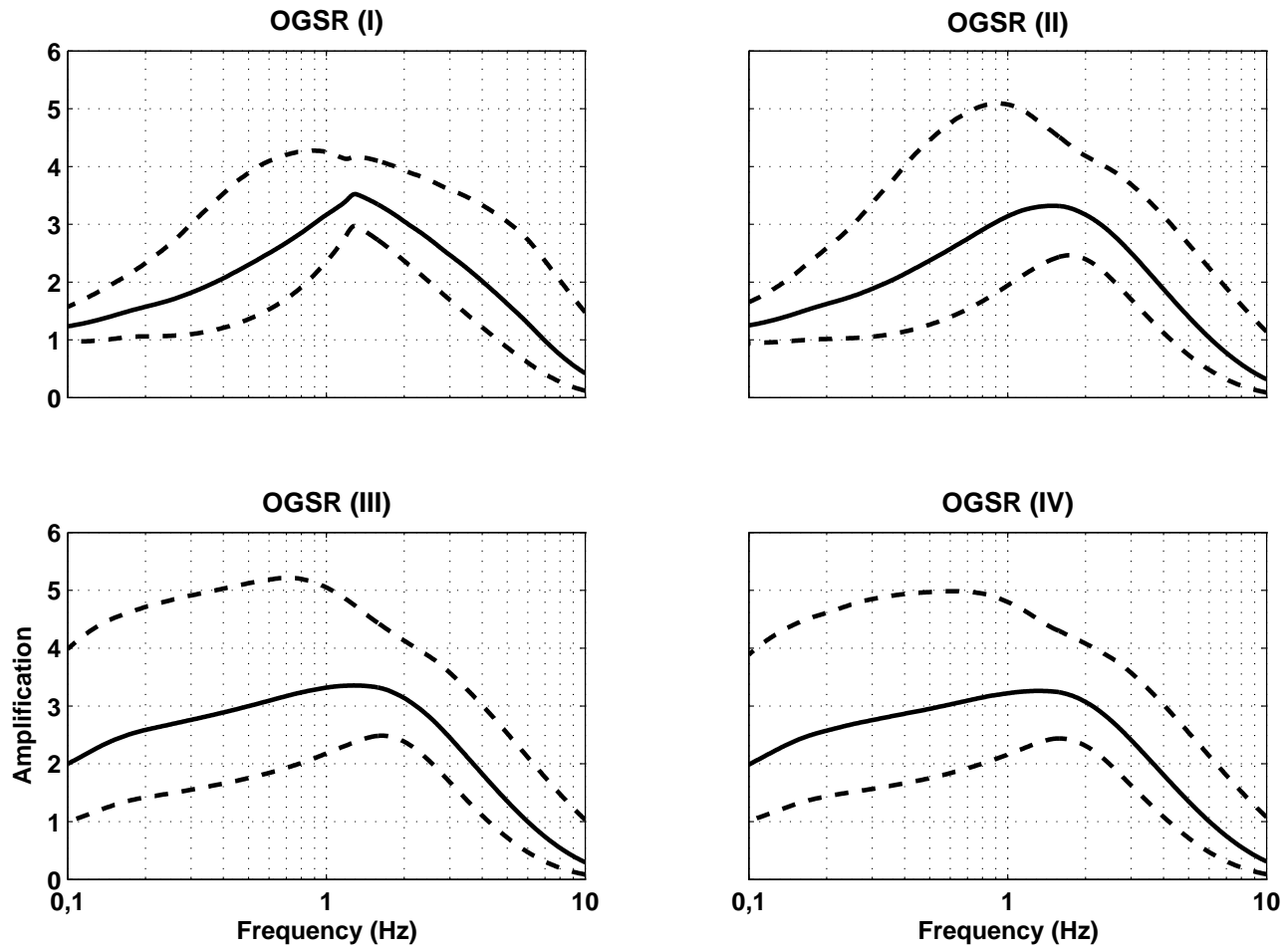
Figure 12: Generated velocity profiles for four EC8 site classes and their 10 and $90 \%$ confidence limits (dashed lines). The grey solid line represents the velocity profile given by the generic model of Cotton et al (2006) based on $V_{s, 30}$.
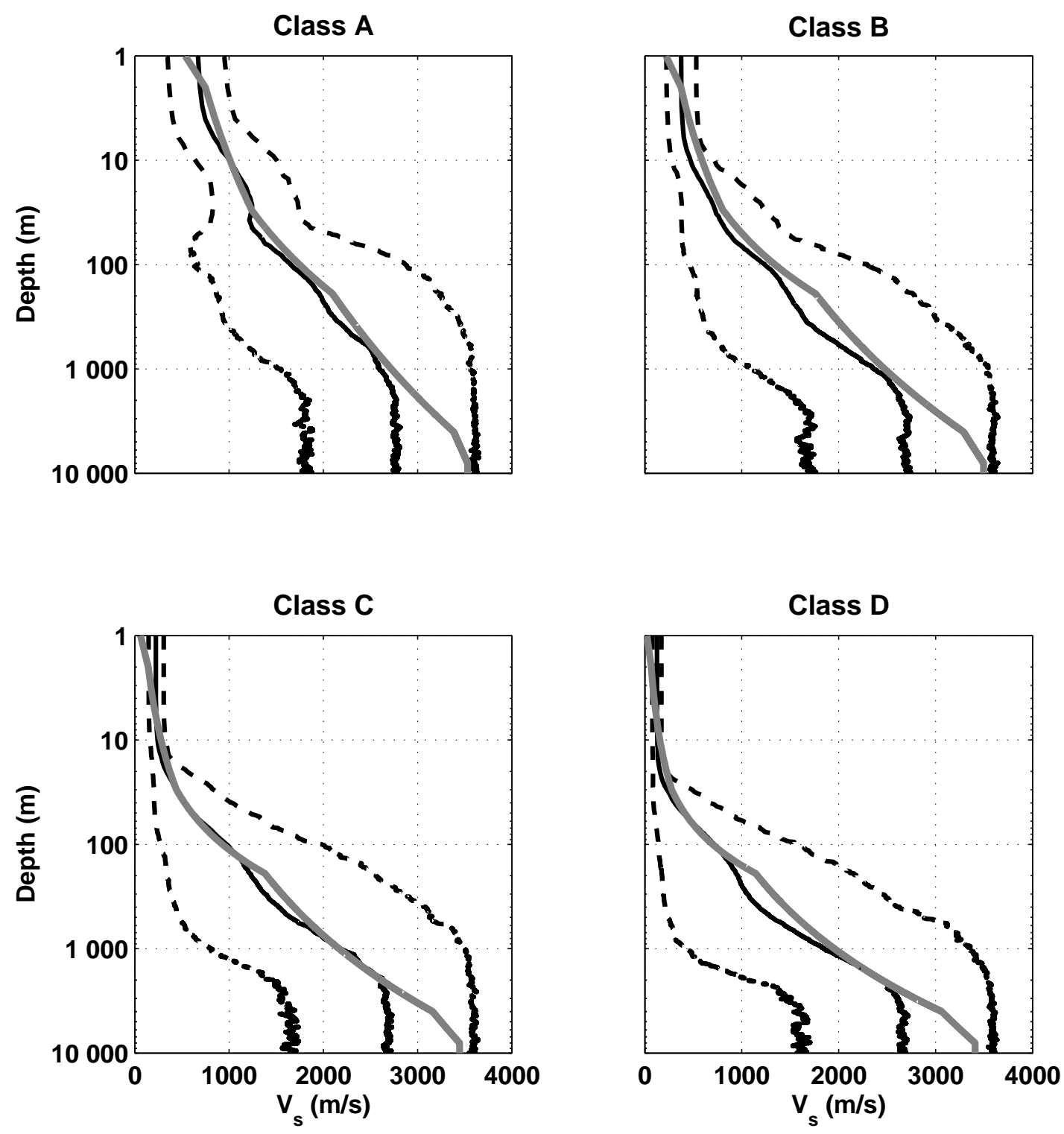
Figure 13: Amplification curves for four EC8 site classes, and their 10 and 90\% confidence limits (dashed lines). The grey solid line represents the amplification curve that was computed using the velocity profile given by the generic model of Cotton et al (2006) based on $V_{s, 30}$.
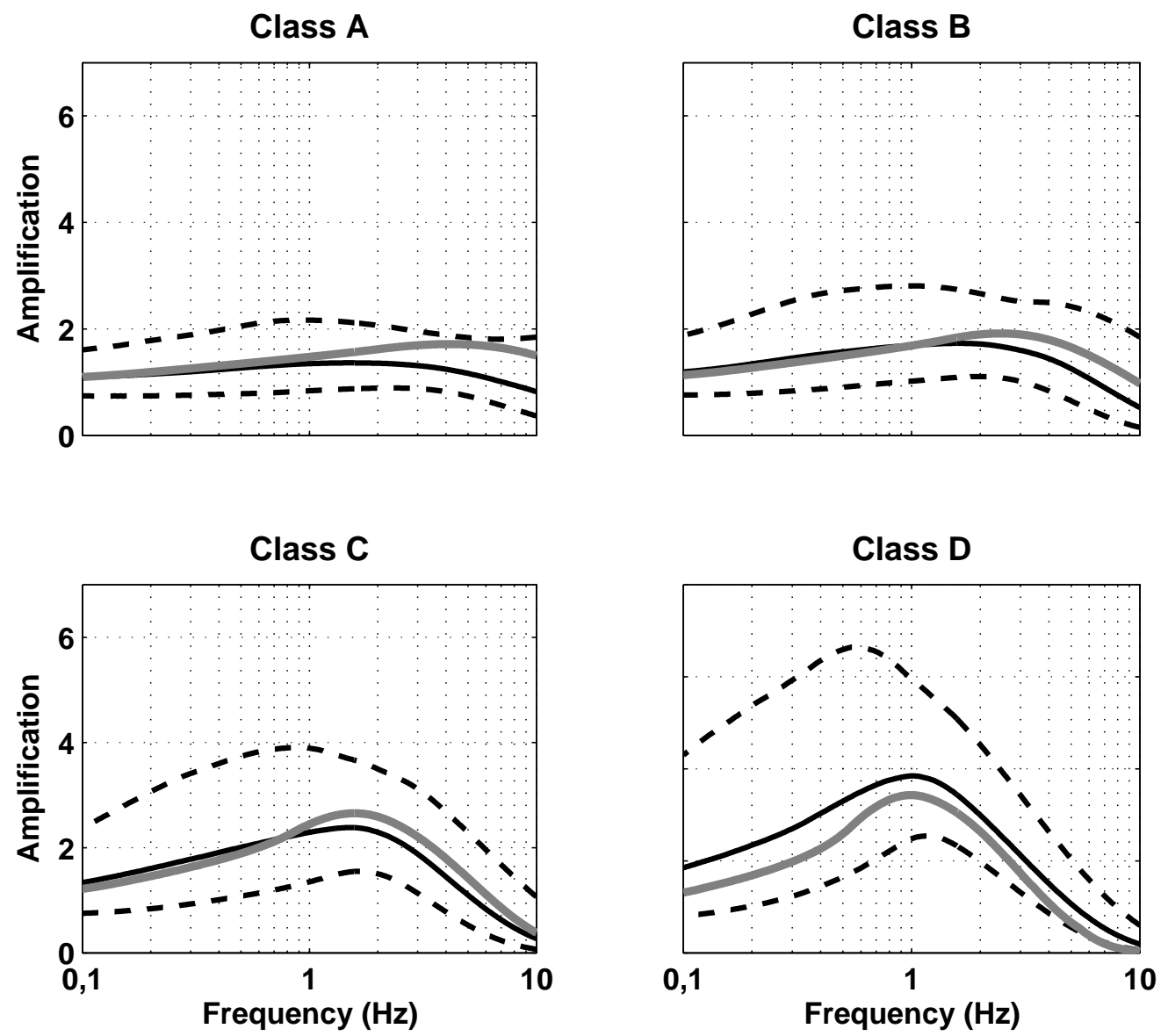
Figure 14: Comparison between the mean amplification curve and its 10 and $90 \%$ confidence limits computed using the one-quarter wavelength method (thick lines) and the mean amplification curve and its 10 and 90\% confidence limits computed using the Haskell-Thompson method (thin lines) for the OGDH station. The profiles simulated using the Monte Carlo technique developed in this article are used for both computations.

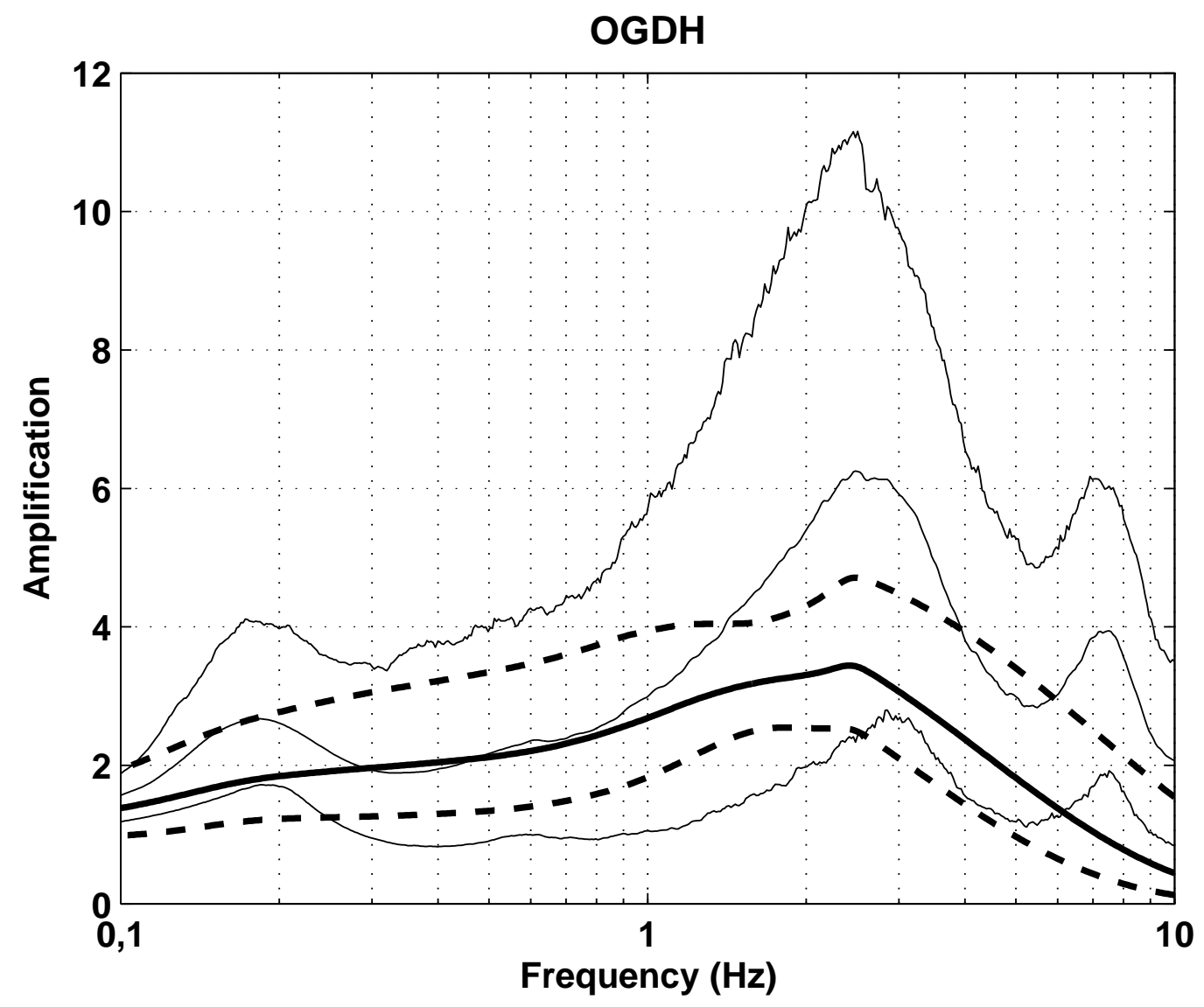




\section{List of Tables}

1 Information available to constrain shear-wave velocity and density profiles down to a few kms.................................... 41

2 Correlation coefficients between different characteristics of the observed profiles. 42

3 Strong-motion stations of the RAP considered in this study and the information available to constrain the shear-wave velocity and density profiles down to a few kms. Italics indicate those data that were not used to constrain the profiles in this study. . . . . . . . . . . . . . . . . . . . 43

4 Computed mean $V_{s, \frac{1}{4}}$ and its 10 and 90th percentile confidence limits for the 14 RAP stations and the four EC8 site classes for different spectral periods. . . . . 44 
Table 1: Information available to constrain shear-wave velocity and density profiles down to a few kms.

\begin{tabular}{ll}
\hline Type of information & Examples \\
\hline Soil profile & BRGM (2008b) \\
Crustal structure & Souriau and Granet (1995), CRUST2.0 (Laske et al, \\
& 2005) \\
Beneric $V_{s}$ profile & $\begin{array}{l}\text { Boore and Joyner (1991), Anderson et al (1996), Boore } \\
\text { and Joyner (1997), Parolai et al (2002), Chandler et al } \\
\\
\text { (2005), Chandler et al (2006), Cotton et al (2006) }\end{array}$ \\
Reasured $V_{s}$ profile & National/region/local geological maps (BRGM, \\
Near-surface geology & 2008a), Wills et al (2000) \\
& Souriau et al (2007) \\
Microtremor measurements & Borcherdt (1994), Comité Européen de Normalisation \\
Site class & (2005) \\
& Wei et al (1996), Hasancebi and Ulusay (2007) \\
Standard penetration test (SPT) & Andrus et al (2004) \\
Cone penetration test (CPT) & Wald and Allen (2007) \\
Topographic slope & Vallon (1999), Parolai et al (2002) \\
$\begin{array}{l}\text { Depth to bedrock (from, e.g., } \\
\text { Bouguer gravity data or H/V re- }\end{array}$ & \\
sults) & \\
\hline
\end{tabular}


Table 2: Correlation coefficients between different characteristics of the observed profiles.

\begin{tabular}{lllll}
\hline & $V_{s}$ & Depth to top of layer & Layer thickness & Slope \\
\hline$V_{s}$ & 1 & 0.4519 & 0.4152 & -0.2089 \\
Depth to top of layer & 1 & 0.7295 & -0.2505 \\
Layer thickness & & & 1 & -0.1861 \\
Slope & & & 1 \\
\hline
\end{tabular}


Table 3: Strong-motion stations of the RAP considered in this study and the information available to constrain the shear-wave velocity and density profiles down to a few kms. Italics indicate those data that were not used to constrain the profiles in this study.

\begin{tabular}{|c|c|c|c|}
\hline Station & Latitude & Longitude & Information available \\
\hline NALS & $43.699 \mathrm{~N}$ & $7.258 \mathrm{E}$ & $\begin{array}{l}\text { Surface geology, soil profile down to } 39 \mathrm{~m} \text {, SPT down to } 39 \mathrm{~m} \text {, } \\
H / V \text { noise spectrum (Bard et al, 2005), crustal structure (Laske } \\
\text { et al, 2005), topographic slope (Wald and Allen, 2007), site class } \\
\text { (soil) }\end{array}$ \\
\hline NLIB & $43.710 \mathrm{~N}$ & $7.264 \mathrm{E}$ & $\begin{array}{l}\text { Surface geology, soil profile down to } 39 \mathrm{~m} \text {, SPT down to } 39 \mathrm{~m} \text {, } \\
H / V \text { noise spectrum (Bard et al, 2005), crustal structure (Laske } \\
\text { et al, 2005), topographic slope (Wald and Allen, 2007), site class } \\
\text { (soil) }\end{array}$ \\
\hline NPOR & $43.700 \mathrm{~N}$ & $7.286 \mathrm{E}$ & $\begin{array}{l}\text { Surface geology, soil profile down to } 39 \mathrm{~m} \text {, SPT down to } 39 \mathrm{~m} \text {, } \\
H / V \text { noise spectrum (Bard et al, 2005), crustal structure (Laske } \\
\text { et al, 2005), topographic slope (Wald and Allen, 2007), site class } \\
\text { (soil) }\end{array}$ \\
\hline NROC & $43.716 \mathrm{~N}$ & $7.293 \mathrm{E}$ & $\begin{array}{l}\text { Surface geology, soil profile down to } 39 \mathrm{~m} \text {, SPT down to } 39 \mathrm{~m} \text {, } \\
H / V \text { noise spectrum (Bard et al, 2005), crustal structure (Laske } \\
\text { et al, 2005), topographic slope (Wald and Allen, 2007), site class } \\
\text { (soil) }\end{array}$ \\
\hline OCKE & $45.771 \mathrm{~N}$ & $3.088 \mathrm{E}$ & $\begin{array}{l}\text { Surface geology, soil profile down to } 12 \mathrm{~m} \text {, SPT down to } 9 \mathrm{~m}, H / V \\
\text { noise spectrum, crustal structure (Laske et al, 2005), topographic } \\
\text { slope (Wald and Allen, 2007), site class (soil) }\end{array}$ \\
\hline OCOR & $45.798 \mathrm{~N}$ & $3.028 \mathrm{E}$ & $\begin{array}{l}\text { Surface geology, soil profile down to } 11 \mathrm{~m}, H / V \text { noise and earth- } \\
\text { quake spectra, crustal structure (Laske et al, 2005), topographic } \\
\text { slope (Wald and Allen, 2007), site class (rock) }\end{array}$ \\
\hline OGBB & $44.281 \mathrm{~N}$ & $5.26 \mathrm{E}$ & $\begin{array}{l}\text { Surface geology, soil profile down to } 12.2 \mathrm{~m} \text {, crustal structure } \\
\text { (Laske et al, 2005), topographic slope (Wald and Allen, 2007), } \\
\text { site class (rock) }\end{array}$ \\
\hline OGDH & $45.182 \mathrm{~N}$ & $5.737 \mathrm{E}$ & $\begin{array}{l}\text { Surface geology, soil profile down to } 15 \mathrm{~m} \text {, SPT down to } 39 \mathrm{~m}, H / V \\
\text { noise and earthquake spectra, depth to bedrock (Vallon, 1999), } \\
\text { crustal structure (Laske et al, 2005), topographic slope (Wald and } \\
\text { Allen, 2007), site class (soil) }\end{array}$ \\
\hline OGLP & $44.307 \mathrm{~N}$ & $4.69 \mathrm{E}$ & $\begin{array}{l}\text { Surface geology, soil profile down to } 10 \mathrm{~m}, \mathrm{SPT} \text { down to } 13 \mathrm{~m}, H / V \\
\text { noise spectrum, crustal structure (Laske et al, 2005), topographic } \\
\text { slope (Wald and Allen, 2007), site class (soil) }\end{array}$ \\
\hline OGMU & $45.195 \mathrm{~N}$ & $5.727 \mathrm{E}$ & $\begin{array}{l}\text { Surface geology, } H / V \text { noise and earthquake spectra, crustal struc- } \\
\text { ture (Laske et al, 2005), topographic slope (Wald and Allen, 2007), } \\
\text { site class (rock) }\end{array}$ \\
\hline OGSR & $45.193 \mathrm{~N}$ & $5.74 \mathrm{E}$ & $\begin{array}{l}\text { Surface geology, soil profile down to } 50 \mathrm{~m}, H / V \text { noise and earth- } \\
\text { quake spectra, depth to bedrock (Vallon, 1999), crustal structure } \\
\text { (Laske et al, 2005), topographic slope (Wald and Allen, 2007), site } \\
\text { class (soil) }\end{array}$ \\
\hline PYFE & $42.814 \mathrm{~N}$ & $2.507 \mathrm{E}$ & $\begin{array}{l}\text { Surface geology, soil profile down to } 11 \mathrm{~m}, H / V \text { noise and earth- } \\
\text { quake spectra, crustal structure (Laske et al, 2005), topographic } \\
\text { slope (Wald and Allen, 2007), site class (soil) }\end{array}$ \\
\hline PYFO & $42.968 \mathrm{~N}$ & $1.607 \mathrm{E}$ & $\begin{array}{l}\text { Surface geology, } H / V \text { noise and earthquake spectra, crustal struc- } \\
\text { ture (Laske et al, 2005), topographic slope (Wald and Allen, 2007), } \\
\text { site class (soil) }\end{array}$ \\
\hline PYPE & $42.673 \mathrm{~N}$ & $2.878 \mathrm{E}$ & $\begin{array}{l}\text { Surface geology, soil profile down to } 78.5 \mathrm{~m}, H / V \text { noise and earth- } \\
\text { quake spectra, crustal structure (Laske et al, 2005), topographic } \\
\text { slope (Wald and Allen, 2007), site class (soil) }\end{array}$ \\
\hline
\end{tabular}


Table 4: Computed mean $V_{s, \frac{1}{4}}$ and its 10 and 90th percentile confidence limits for the 14 RAP stations and the four EC8 site classes for different spectral periods.

\begin{tabular}{|c|c|c|c|c|c|c|c|c|}
\hline \multirow[t]{2}{*}{ Station } & \multirow{2}{*}{$\begin{array}{l}\text { Statistical } \\
\text { measure }\end{array}$} & \multicolumn{7}{|c|}{$V_{s, \frac{1}{4}}$} \\
\hline & & $0.1 \mathrm{~s}$ & $0.2 \mathrm{~s}$ & $0.5 \mathrm{~s}$ & $1 \mathrm{~s}$ & $2 \mathrm{~s}$ & $5 \mathrm{~s}$ & $10 \mathrm{~s}$ \\
\hline \multirow[t]{3}{*}{ NALS } & mean & 175 & 211 & 959 & 1731 & 2528 & 2920 & 3203 \\
\hline & 10th percentile & 141 & 193 & 446 & 782 & 1215 & 2234 & 2730 \\
\hline & 90th percentile & 209 & 275 & 1768 & 2696 & 3216 & 3353 & 3550 \\
\hline \multirow[t]{3}{*}{ NLIB } & mean & 241 & 384 & 1306 & 1958 & 2676 & 2981 & 3235 \\
\hline & 10th percentile & 208 & 291 & 735 & 1037 & 1513 & 2358 & 2793 \\
\hline & 90th percentile & 272 & 571 & 2191 & 2923 & 3328 & 3398 & 3572 \\
\hline \multirow[t]{3}{*}{ NPOR } & mean & 209 & 177 & 981 & 1761 & 2549 & 2929 & 3207 \\
\hline & 10th percentile & 196 & 167 & 567 & 924 & 1416 & 2320 & 2774 \\
\hline & 90th percentile & 220 & 187 & 1724 & 2666 & 3200 & 3347 & 3547 \\
\hline \multirow[t]{3}{*}{ NROC } & mean & 252 & 269 & 637 & 1051 & 1928 & 2680 & 3083 \\
\hline & 10th percentile & 235 & 220 & 208 & 210 & 221 & 358 & 1603 \\
\hline & 90th percentile & 266 & 406 & 1692 & 2613 & 3173 & 3335 & 3539 \\
\hline \multirow[t]{3}{*}{$\overline{\mathrm{OCKE}}$} & mean & 151 & 207 & 889 & 1477 & 2321 & 2849 & 3186 \\
\hline & 10th percentile & 114 & 133 & 153 & 210 & 283 & 1034 & 2065 \\
\hline & 90th percentile & 195 & 714 & 2298 & 2965 & 3350 & 3411 & 3582 \\
\hline \multirow[t]{3}{*}{ OCOR } & mean & 149 & 209 & 950 & 1534 & 2356 & 2862 & 3190 \\
\hline & 10th percentile & 109 & 129 & 150 & 221 & 305 & 1097 & 2095 \\
\hline & 90th percentile & 193 & 780 & 2353 & 2988 & 3362 & 3413 & 3581 \\
\hline \multirow[t]{3}{*}{ OGBB } & mea & 157 & 208 & 743 & 1133 & 1635 & 2559 & 3024 \\
\hline & rcentile & 116 & 134 & 154 & 208 & 275 & 686 & 1862 \\
\hline & 90th percentile & 197 & 620 & 1724 & 2146 & 2831 & 3201 & 3475 \\
\hline \multirow[t]{3}{*}{$\overline{\mathrm{OGDH}}$} & mean & 129 & 317 & 1023 & 1472 & 2034 & 2724 & 3107 \\
\hline & 10th percentile & 96 & 181 & 318 & 433 & 762 & 1918 & 2483 \\
\hline & ercentile & 194 & 808 & 1904 & 2259 & 2910 & 3231 & 3489 \\
\hline \multirow[t]{3}{*}{$\overline{\text { OGLP }}$} & mean & 202 & 328 & 950 & 1295 & 1809 & 2632 & 3058 \\
\hline & 10th percentile & 153 & 151 & 165 & 238 & 337 & 1025 & 2036 \\
\hline & 90th p & 281 & 1166 & 1974 & 2281 & 2926 & 3236 & 3491 \\
\hline \multirow[t]{3}{*}{ OGMU } & mean & 939 & 1122 & 1345 & 1549 & 2061 & 2734 & 3110 \\
\hline & 10th percentile & 514 & 517 & 503 & 529 & 636 & 1647 & 2348 \\
\hline & 90th percentile & 1722 & 2046 & 2323 & 2466 & 3056 & 3288 & 3517 \\
\hline \multirow[t]{3}{*}{ OGSR } & mea & 206 & 256 & 1018 & 1755 & 2369 & 2857 & 3172 \\
\hline & 10th percentile & 149 & 192 & 250 & 377 & 1327 & 2221 & 2726 \\
\hline & 90th percentile & 267 & 522 & 1755 & 2227 & 2889 & 3221 & 3482 \\
\hline \multirow[t]{3}{*}{ PYFE } & mea & 163 & 214 & 882 & 1415 & 2042 & 2680 & 3078 \\
\hline & 10 th & 125 & 133 & 146 & 194 & 268 & 661 & 1813 \\
\hline & 90th percentile & 207 & 791 & 2232 & 2805 & 3166 & 3319 & 3529 \\
\hline \multirow[t]{3}{*}{ PYFO } & mean & 953 & 1185 & 1520 & 1842 & 2289 & 2749 & 3104 \\
\hline & 10 th p & 512 & 521 & 524 & 560 & 710 & 1586 & 2294 \\
\hline & 90th p & 1844 & 2329 & 2810 & 3030 & 3198 & 3322 & 3529 \\
\hline \multirow[t]{3}{*}{$\overline{\mathrm{PYPE}}$} & mean & 160 & 217 & 429 & 779 & 1451 & 2399 & 2923 \\
\hline & 10 th p & 115 & 157 & 227 & 257 & 290 & 536 & 1679 \\
\hline & 90th percentile & 206 & 283 & 950 & 2026 & 2748 & 3131 & 3429 \\
\hline EC8 class A & mean & 1307 & 1633 & 2102 & 2408 & 2584 & 2526 & 2672 \\
\hline & 10th per & 662 & 645 & 787 & 991 & 1352 & 1628 & 1659 \\
\hline & 90th percentile & 2456 & 2946 & 3325 & 3464 & 3539 & 3421 & 3537 \\
\hline EC8 class B & mean & 625 & 932 & 1422 & 1923 & 2306 & 2366 & 2558 \\
\hline & 10th p & 300 & 339 & 426 & 516 & 754 & 1279 & 1409 \\
\hline & 90th percentile & 1413 & 2144 & 2921 & 3256 & 3422 & 3367 & 3507 \\
\hline EC8 class $\mathrm{C}$ & mean & 262 & 422 & 926 & 1477 & 2044 & 2254 & 2493 \\
\hline & 10 th pe & 154 & 173 & 203 & 263 & 351 & 891 & 1193 \\
\hline & 90th percentile & 537 & 1308 & 2485 & 3025 & 3309 & 3320 & 3482 \\
\hline EC8 class D & mean & 127 & 139 & 389 & 811 & 1518 & 2023 & 2372 \\
\hline & 10 th p & 79 & 79 & 82 & 95 & 128 & 205 & 708 \\
\hline & 90th percentile & 172 & 306 & 1550 & 2500 & 3042 & 3209 & 3423 \\
\hline
\end{tabular}

